RELEASED FOR ANNOUNCEMENT

IN NUCLEAR SCIENCE ABSTRACTS

\title{
FLUX MAPPING MEASUREMENTS \\ TO DETERMINE THE LOCATION OF THE PERMANENT DETECTORS IN THE ENRICO FERMI REACTOR
}

\section{APDA-NTS-8}




\section{DISCLAIMER}

This report was prepared as an account of work sponsored by an agency of the United States Government. Neither the United States Government nor any agency Thereof, nor any of their employees, makes any warranty, express or implied, or assumes any legal liability or responsibility for the accuracy, completeness, or usefulness of any information, apparatus, product, or process disclosed, or represents that its use would not infringe privately owned rights. Reference herein to any specific commercial product, process, or service by trade name, trademark, manufacturer, or otherwise does not necessarily constitute or imply its endorsement, recommendation, or favoring by the United States Government or any agency thereof. The views and opinions of authors expressed herein do not necessarily state or reflect those of the United States Government or any agency thereof. 


\section{DISCLAIMER}

Portions of this document may be illegible in electronic image products. Images are produced from the best available original document. 
0

$C$ 


\section{FOREWORD}

This report is one of a series of reports on the low-power (up to $1 \mathrm{Mwt}$ ) and high-power (up to $200 \mathrm{Mwt}$ ) nuclear testing of the Enrico Fermi reactor. The Nuclear Test Program is planned, directed and evaluated by Atomic Power Development Associates, Inc. (APDA). The tests are conducted by Power Reactor Development Company (PRDC). The reactor proper is owned and operated by PRDC. The steam generators and electrical generation facilities are owned by The Detroit Edison Company (DECo).

Many people have contributed to the success of the nuclear testing of the Fermi reactor. Listed below are the names of those people, exclusive of the authors, who made a significant contribution to some phase of the work reported in this document.

APDA

R. J. Beaudry
PRDC

P. M. Harrigan

J. Nyquist

W. Hill

J. Herb
DECO

J. Levine 
0 
TABLE OF CONTENTS

Section

$\underline{\text { Title }}$

Page

LIST OF ILLUSTRATIONS .................. 7

LIST OF TABLES $\ldots \ldots \ldots \ldots \ldots \ldots \ldots \ldots \ldots \ldots$

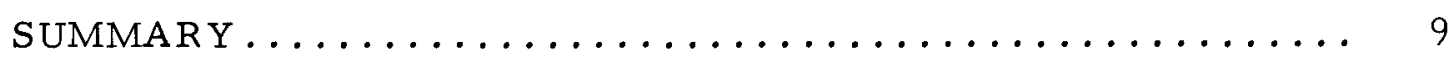

I PURPOSE OF TEST $\ldots \ldots \ldots \ldots \ldots \ldots \ldots \ldots \ldots \ldots \ldots \ldots \ldots$

II DESCRIPTION OF THE ENRICO FERMI REACTOR ....... 13

A. GENERAL DESCRIPTION ................... 13

B. DESCRIPTION OF THE NEUTRON COUNTER TUBES .... 16

C. DESCRIPTION OF THE PERMANENT PLANT NEUTRON DETECTION SYSTEM ................ 19

D. DESCRIPTION OF THE TEMPORARY STARTUP INSTRUMENTATION SYSTEM ................ 19

E. DESCRIPTION OF THE TEST INSTRUMENTATION

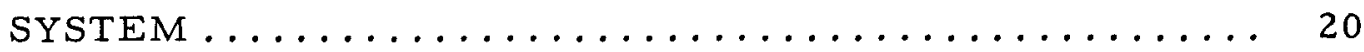

III EXPERIMENTAL PROCEDURE $\ldots \ldots \ldots \ldots \ldots \ldots \ldots \ldots \ldots$

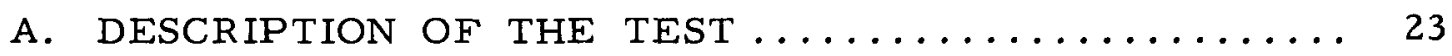

1. Measurement of the Neutron Detector Responses...... 23

a. Relative Detector Responses ............... 23

b. Absolute Detector Responses ............... 25

2. Shutdown Power Level Determination .............. 26

3. Shutdown Gamma Dose Determination ........... 26

B. EXPERIMENTAL EQUIPMENT ............... 27

C. REACTOR PLANT CONDITIONS .............. 28

IV EXPERIMENTAL RESULTS AND DATA REDUCTION ...... 31

A. NEUTRON DETECTOR RESPONSE MEASUREMENTS .... 31

1. Relative Detector Responses ................. 31

2. Absolute Detector Responses ................ 37

3. Shadowed Responses of Permanent Plant

Intermediate Range Ion Chambers ............ 40

4. Power Calibration Data ................. 4u

B. SUPPLEMENTAL NEUTRON DETECTOR RESPONSE MEASUREMENTS ..................... 41

1. Cadmium Ratio Measurements ................ 41

2. Polyethylene Moderator Measurements ............ 42 
C. SHUTDOWN POWER LEVEL MEASUREMENTS ........ 47

1. Evaluation of Shutdown Power Level ............ 47

2. Uncertainty in Evaluation................... 49

3. Dependence on Number of Installed Safety Rods ....... 49

D. SHUTDOWN GAMMA DOSE MEASUREMENTS.......... 50

$V$ DATA ANALYSIS AND DISCUSSION OF RESULTS . . . . . . 53

A. PERMANENT PLANT DETECTOR LOCATIONS

AND MINIMUM SOUR CE SIZE REQUIRED .......... 53

1. General Ground Rules .................... 53

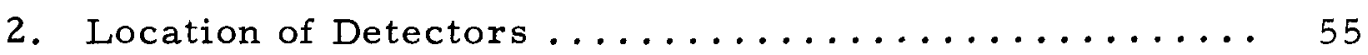

a. Location of Intermediate Range Channels ....... 55

b. Location of Source Range Channels............ 56

c. Location of Power Range Channels ........... 57

3. Minimum Source Size ..................... 58

4. Summary of Permanent Plant Detector Positions...... 58

5. Summary of Permanent Plant Detector Responses..... 60

B. SENSITIVITY INCREASE OF SOURCE RANGE

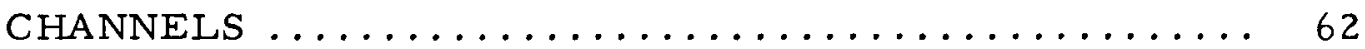

C. CADMIUM RATIO MEASUREMENTS .............. 63

D. GAMMA DOSE RATE AT DETECTOR LOCATIONS....... 64

1. Shutdown Gamma Dose Rates .................. 65

a. Scaling Factor for Maximum Conditions ........ 65

b. Dose on Source Range Detectors ............. 66

c. Dose on Intermediate Range Detectors.......... 66

2. Operating Gamma Dose Rates................ 67

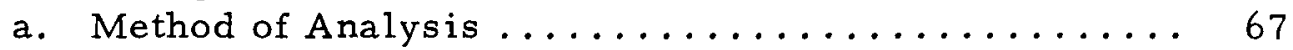

b. Dose on Power Range Detectors ............ 68

3. Source of Shutdown Gammas .................. 69

E. COMPARISON WITH CALCULATION ............ 70

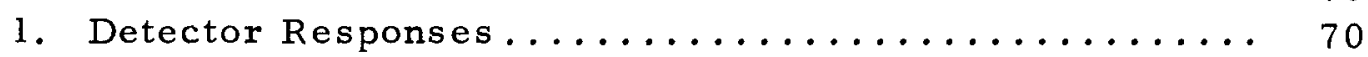

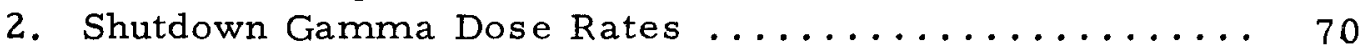

3. Operating Gamma Dose Rates................ 72

4. Minimum Source Size ................... 72

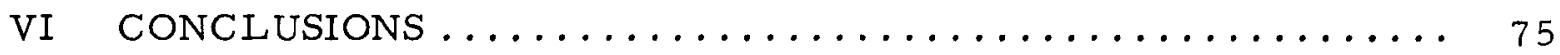

REFERENCES $\ldots \ldots \ldots \ldots \ldots \ldots \ldots \ldots \ldots \ldots \ldots \ldots \ldots \ldots \ldots \ldots$ 


\section{LIST OF ILLUSTRATIONS}

Figure

Title

Page

1 Perspective View of Reactor ............... 14

2 Reactor Cross Section................ 15

3 Location of Neutron-Counter Tubes and Sodium Pipes in

Graphite Shield .................. 17

4 Typical Penetration of Neutron-Counter Tubes through

Reactor Vessel . . . . . . . . . . . . . . 18

5 Temporary Detector Positions in Neutron-Counter Tubes

3 and 4 ......................

6 Relative Boron Response Distributions in the NeutronCounter Tubes Using a Reuter-Stokes $\mathrm{BF}_{3}$ Proportional Counter. . . . . . . . . . . . . . . . . .

7 Relative Boron Response Distributions in Neutron-Counter Tubes 2 and 4 using an Anton $\mathrm{BF}_{3}$ Proportional Counter Bare and Inside an Open Candmium Can . . . . . . . . . . .

8 Relative Boron Response Distributions in Neutron-Counter Tubes 1 and 2 using an Anton $\mathrm{BF}_{3}$ Proportional Counter Bare and Inside a Closed Cadmium Can . . . . . . . . . .

9 Relative U-235 Fission Response Distributions in NeutronCounter Tubes 2, 3, and 4 using a Westinghouse Fission Counter Bare and Inside an Open Cadmium Can . . . . . .

10 Cadmium Ratios in Neutron-Counter Tubes 1 and 2....

11 Shield Structure Near Neutron-Counter Tube 1. . . . .

12 Shield Structure Near Neutron-Counter Tube 2.......

13 Effect of Polyethylene on Fission Counter Response in Neutron-Counter Tubes 2 and 4 ............ . 46

14 Decay Curve for Antimony-Beryllium Source No. 2 . . . . 48 


\section{LIST OF ILLUSTRA TIONS (Continued)}

Figure

Title

Page

15 Shutdown Gamma Dose Rate Axial Distribution in Neutron-

Counter Tubes 3.7 Hours after Reactor Shutdown . . . . . 52

16 Predicted Reactor Power Coverage with the Permanent

Plant Instrumentation . . . . . . . . . . . . . 61

17 Shutdown Gamma Dose Rates in Neutron-Counter Tubes 1

and 2 as a Function of Time after Shutdown . . . . . . 70

\section{LIST OF TABLES}

Table

Title

Page

I

Neutron Detector Characteristics . . . . . . . . . .

II Neutron Detector Electronics . . . . . . . . . . 28

III Elevation and Angle of Neutron Counter Tubes . . . . . 36

IV Absolute Detector Calibration Data Obtained at Bottom of

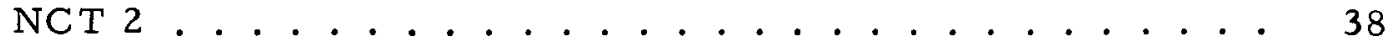

$\mathrm{V} \quad$ Absolute Detector Response in NCT 2 .......... 39

VI Reactor Power Calibration Data for Temporary Startup

Instrumentation . . . . . . . . . . . . . . 4 41

VII Final Positions of Permanent Plant Neutron Detectors . . . 59

VIII Elevations of Neutron Detector Racks. .......... 60

IX Measured Response of As-Installed Permanent Plant

Neutron Detectors . . . . . . . . . . . . . 62

X Operating Gamma Dose Rates at Power Range Detector

Positions at $300 \mathrm{Mwt}$. . . . . . . . . . . . 68

XI Shutdown Gamma Dose Rates in Neutron Counter Tubes at

Core Midplane Elevation . . . . . . . . . . . . . . 


\section{SUMMARY}

The majority of the tests in which flux mapping measurements were made in the Fermi reactor were made during the months of November and December 1963. A few tests were also made during 1964. In the tests, the axial distribution of the relative boron-10 $(n, a)$ response was obtained in all six of the neutron counter tubes which are located in the graphite shield and which are designed to contain the permanent plant instrumentation. The axial distribution of the relative $U-235$ fission response in counter tubes numbers 2, 3, and 4 was obtained as well. Measurements were also made of the effect of wrapping the detectors with cadmium absorber material and polyethylene moderator material. The absolute response of each type of permanent plant neutron detector (boron-lined ion chambers and U-235 fission counters) was then obtained at a known power level for at least one position in the counter tubes of interest. The two sets of data were combined and analyzed and the results were used to locate each of the thirteen neutron detectors to be used for permanent plant operation. ${ }^{*}$ In addition, the data were used to determine the antimony-beryllium neutron source size needed to produce a minimum of $10 \mathrm{cps}$ at shutdown on source range channels 1 and 2 . This is the minimum count rate specified for reactor startup. The source size obtained was 743 curies. ** Finally, the shutdown gamma radiation level in all of the neutron counter tubes was measured following a period of short-term low-power reactor operation. These data were extrapolated to obtain the expected shutdown gamma radiation levels following long-term operation at full power, and it was verified that neither the source range or intermediate range channels would be adversely affected by gamma interference during reactor startup. A similar analysis was also made of the effect of gamma radiation on the operation of the Power Range channels using operational gamma radiation data which had been determined as part of the shield test program.

The measured results of the flux mapping tests agreed with predictions to within the accuracy expected, although the predictions did have a rather large uncertainty to them because they were based on shielding type calculations. Nevertheless, the only major consequence of this was that the measured neutron detector sensitivities in counter tubes 1 and 6 were sufficiently below the predicted values to require a slight revision in the original design of the power range channel electronics.

* Since the completion of the analyses reported here, two additional source range detectors and two absolute fission counters have been added to the permanent plant instrumentation system.

** Since the completion of the analyses reported here, the minimum specified count rate was changed to $5 \mathrm{cps}$ resulting in a corresponding change in minimum source size to 371 curies. 
- 


\section{PURPOSE OF TEST}

The primary purpose of the flux mapping tests was to obtain the permanent plant neutron detector responses as a function of axial position in the six neutron counter tubes. This information was then used to determine the proper placement of the detectors in the permanent instrument racks such that the desired response over the full power range of reactor operation would be achieved. The data were also used to determine the neutron source strength required for safe reactor startup. In addition, the gamma radiation levels in the counter tubes both during and following reactor operation were analyzed to insure that the positions chosen for the neutron detectors would allow operation without significant interference by gamma radiation. 


\section{DESCRIPTION OF THE ENRICO FERMI REACTOR}

\section{A. GENERAL DESCRIPTION}

The Fermi reactor and its associated structures are shown in perspective in Figure 1. The reactor is contained in a stainless steel reactor vessel sealed at the top by a rotating shield plug which supports the control mechanisms, the fuel subassembly hold-down mechanism, and the fuel subassembly handling mechanism. The reactor vessel is surrounded by borated and plain graphite neutron shielding material which is contained inside the primary shield tank. The reactor is of the fast-breeder type, cooled by sodium, and it is operated at essentially atmospheric pressure. The maximum reactor power obtainable with the first core loading (Core A) is $200 \mathrm{Mwt}$.

The core and blanket a re located in the lower reactor vessel and consist of 2.65-inch square subassemblies containing the fuel pins and blanket rods. The core and blanket subassemblies are arranged to approximate a cylinder about 80 inches in diameter and 70 inches high. The core, which is contained in the central portion of the core subassemblies, approximates a right cylinder 31 inches in diameter and 31 inches high; it is axially and radially surrounded by the breeder blankets. The fuel in the first core loading consists of zirconium-clad pins containing $U-10 \mathrm{w} / 0$ molybdenum alloy with the uranium enriched to $25.6 \mathrm{w} / \mathrm{o} \mathrm{U}-235$. The blanket is depleted U-3 w/o molybdenum alloy.

The reactor cross section, shown in Figure 2, indicates the placement of individual components within the lower reactor vessel. There is a total of 149 central lattice positions that are occupied by core and inner radial blanket subassemblies, the antimony-beryllium ( $\mathrm{Sb}-\mathrm{Be}$ ) neutron source, and the 10 operating control and safety rod channels. All of these positions are supplied with sodium coolant flowing upwards from a high pressure plenum which is connected to the discharge lines of the three primary sodium pumps. The coolant flows upward through the individual core and inne $r$ radial blanket subassemblies and into a large upper plenum. From there it flows by gravity to the three intermediate heat exchangers and then to the suction side of the primary pumps. Sodium also is used in the secondary cooling system.

The lattice positions surrounding the inner radial blanket contain the outer radial blanket subassemblies. Beyond the outer radial blanket are lattice positions used for stainless steel-filled the rmal shield bar subassemblies. These subassemblies provide thermal and neutron shielding for the reactor vessel. The outer radial blanket and shielding lattice positions are both supplied with sodium coolant from a low pressure plenum. 


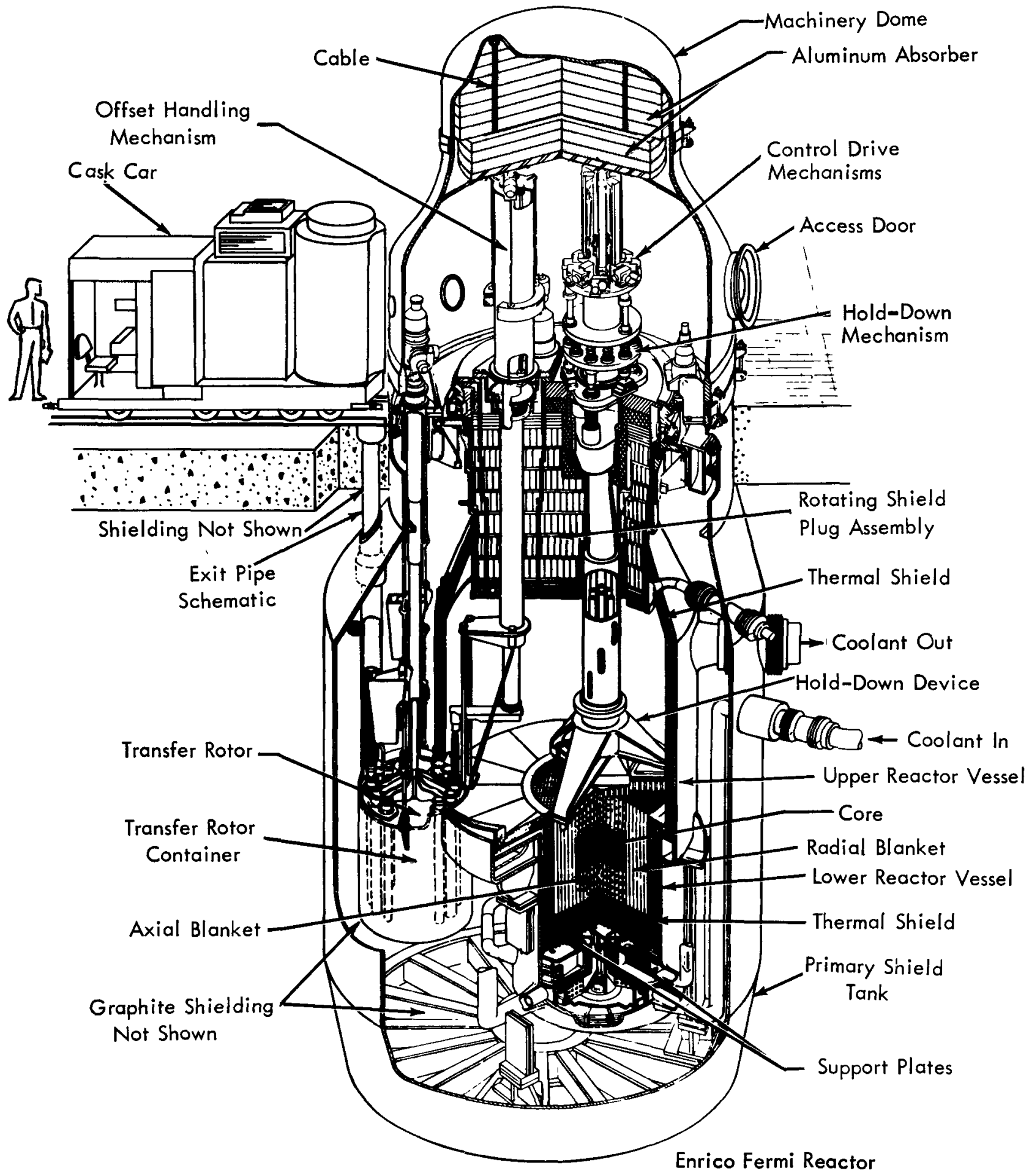

FIG. 1 PERSPECTIVE VIEW OF REACTOR 


\section{○}



Subassembly Clearance

Arrangement

$2.693 \quad 0.047$

$+1+1+1+1$


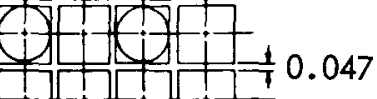

2.693

Thermal Baffles

Thermal Shield Installed

In Segments

Vessel

DESCRIPTION

QUANTITY

Operating Control Rod.

Core Subassembilies .......... 105

Inner Radial Blanket

Subassemblies............. 32

Outer Radial Blanket

Subassemblies... . . . . . . . 499

Possible Storage for Core

or Inner Radial Blanket

Subassemblies............ 24

Thermal Shield in

Form of Steel Rods. . . . . . . . 195

Thermal Shielding in Form

X of Steel Rods Used for

- Surveillance Tubes. . . . . Ö. 3

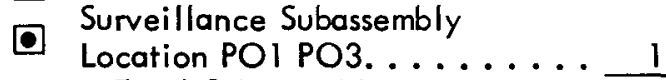

Total Subassemblies. . . . . . . . 870

- Oscillator Rod Temporary

Location PO3POO

FIG. 2 REACTOR CROSS SECTION

The Position Under the Center of the

Rotating Plug is Vacant. 
The reactor is controlled by two operating control rods and seven safety rods which are uniformly spaced around the center of the core. Provisions have also been included in the design for an eighth safety rod. The rods are all of the poison-type, containing boron carbide $\left(\mathrm{B}_{4} \mathrm{C}\right)$ in which the boron is enriched in boron-10 (B-10). One operating control rod is for regulating purposes and the other for shimming. Both rods have approximate reactivity worths of 46 cents. The seven safety rods are worth more than $\$ 1.00$ each and provide shutdown reactivity. During operation of the reactor, they are held just above the upper axial blanket section of the core so that they can be rapidly inserted into the core if it becomes necessary to scram the reactor.

An antimony-beryllium ( $\mathrm{Sb}-\mathrm{Be}$ ) neutron source is located in the reactor, normally at the core-blanket interface (Figure 2), to provide a neutron flux at the neutron detectors during reactor startup and to maintain a flux when the reactor is shut down. The radioactive antimony portion of the source is made as a separate piece for easy replacement and is in the form of a cylindrical rod. The radioantimony rod fits inside a beryllium assembly which is in the form of a hollow cylinder and which is placed inside a stainless steel can having the external dimensions of a normal core subassembly fuel can.

Additional information concerning the reactor design may be found in the Enrico Fermi Hazards Summary Report. ${ }^{1}$

\section{B. DESCRIPTION OF THE NEUTRON COUNTER TUBES}

The permanent neutron detectors required for normal reactor operation are to be located in six neutron counter tubes (NCT) embedded in the graphite neutron shield surrounding the reactor vessel (Figure 3). These tubes penetrate the reactor operating floor and primary shield tank at angles of 6 to 8 degrees from the vertical and extend downward to below the level of the reactor core. Penetration of the primary shield tank is just below the bottom of the operating floor (Figure 4). Borated graphite is kept away from the region of the counter tubes to minimize interference with the response of the detectors. One of the counter tubes (NCT 4) is surrounded by lead shielding over a portion of its length to reduce the gamma background from a nearby sodium coolant pipe (Figure 3). Counter tubes 3 and 4 have plain graphite "neutron windows" installed opposite them in the inner 6-inchthick borated graphite shield layer next to the vessel. The bottom edge of each window is located at the core midplane and they are 2 feet high. Their purpose is to enhance the response of the source range detectors which will be located in these two counter tubes. 




FIG. 3. LOCATION OF NEUTRON - COUNTER TUBES AND SODIUM PIPES IN GRAPHITE SHIELD 




FIG. 4 TYPICAL PENETRATION OF NEUTRON - COUNTER TUBES THROUGH REACTOR VESSEL 


\section{DESCRIPTION OF THE PERMANENT PLANT NEUTRON DETECTION SYSTEM}

To adequately cover the entire reactor power range from shutdown source power to full power $(200 \mathrm{Mwt})$, three separate ranges of power detection will be employed using a total of ten neutron detectors. The three ranges are designated as the source range, intermediate range, and power range. The source range system contains two detection channels, the intermediate range three detection channels, and the power range five detection channels. The two source range channels will be supplied by signals from two two-connector Westinghouse fission chambers located in NCT 3 and are designed to cover the power range from shutdown source power to about 12 $\mathrm{kw}$. The three intermediate range channels will be supplied by signals from three Anton B-10-lined compensated ion chambers located in NCT's 2 and 5 and are designed to operate from approximately $1.2 \mathrm{kw}$ to $1200 \mathrm{Mw}$. Thus, an overlap of one decade with the source range channels is provided. The five power range channels, to be located in NCT's 1, 2 and 6 , will consist of five Anton B-10-lined compensated ion chambers, operated with the detector compensation unconnected, and will cover the power range from approximately $2 \mathrm{Mw}$ to $300 \mathrm{Mw}$ (1 to 150 percent of full power).

In addition to the ten neutron detectors required for normal operation, five other detectors are included in the design. There will be a spare ion chamber for each of the intermediate and power ranges located in NCT's 5 and 6 respectively; there will be an additional power range ion chamber channel located in NCT 6 , connected to a monitor, which will cover the power range from $14 \mathrm{Mw}$ to $1400 \mathrm{Mw}$; and there will be two absolute fission counters located in NCT 3 to verify the linearity of the intermediate range detectors. NCT 4 was to remain vacant for the time being. However, plans now include an additional source range channel located in NCT 4 to extend the coverage to lower powers. (See Section V.B.)

The precise power coverage and specific location of each of the permanent plant detectors described above were determined from the results of this experiment.

\section{DESCRIPTION OF THE TEMPORARY STARTUP INSTRUMENTATION SYSTEM}

During the majority of the low-power nuclear testing on the Fermi reactor, the reactor employed temporary instrumentation which was designated as the temporary startup instrumentation system. It was used in place of the permanent plant instrumentation for two reasons: (1) because the permanent plant source range instrumentation could not be used during the initial loading to criticality due to its relatively low sensitivity, and (2) because the permanent plant instrumentation is rather inflexible and would make shifts in detector positions and detector type a cumbersome procedure. Such 
shifts are desirable to expedite certain experiments (such as the one herein described) and to make the most efficient use of the decaying neutron source. A brief description of the temporary startup instrumentation system follows.

All detectors used for the temporary startup instrumentation system were located in NCT's 3 and 4, leaving NCT's 1, 2, 5 and 6 empty. Two high-sensitivity Twentieth Century Electronics, Ltd., $\mathrm{BF}_{3}$ proportional counters were located in NCT 4 to provide both count rate and period signals to the source range safety system. In addition to these two source range channels, two high-sensitivity Reuter-Stokes, Inc., BF 3 proportional counters, one each in NCT 3 and 4 , were utilized to provide signals to two source range monitoring channels with scaler outputs. These were replaced following initial criticality by two Anton $\mathrm{BF}_{3}$ counters of lower sensitivity so as to extend their useful range to higher powers. Neutron signals to the safety system over the intermediate range were provided by one Anton and two General Electric B-10-lined ion chambers. One General Electric chamber was normally located in NCT 4 and the other two in NCT 3. Power range coverage was accomplished by two Anton B-10-lined ion chambers, one each in NCT 3 and 4 . Although the reactor power was never allowed to exceed one megawatt during the low-power tests, these chambers were required as part of the safety system. Finally, an additional General Electric ion chamber was located in NCT 3 and connected to a Keithley micro-microammeter recorder to provide an additional monitoring channel capable of accurate readout at relatively high powers. Polyethylene surrounded all the ion chambers to enhance their sensitivity. All detectors and detector elevations were easily changeable, and several changes were made both during and subsequent to the experiments described in this report. A schematic diagram of the positions of the temporary instrumentation as of September 11 , 1963, is given in Figure 5.

\section{E. DESCRIPTION OF THE TEST INSTRUMENTATION SYSTEM}

The purpose of the present test was to obtain the permanent plant neutron detector response as a function of axial position in the neutron counter tubes of interest. However, since most of the permanent plant detectors were not available at the time of this experiment, it was necessary to use additional detectors and electronics that were not part of either the permanent or temporary instrumentation system. For example, most of the relative responses as a function of elevation were obtained with detectors of types 2,3 , and 4 of Table I. Where absolute response measurements were required, detectors were chosen that possessed approximately the same sensitivity as expected from the corresponding permanent plant detector. Specifically, detector types 4 and 6 in Table I were assumed to have permanent plant detector sensitivity for the source range channels and intermediate and power range channels, respectively.

Additional information on the test instrumentation system is given in Section IIIB. 


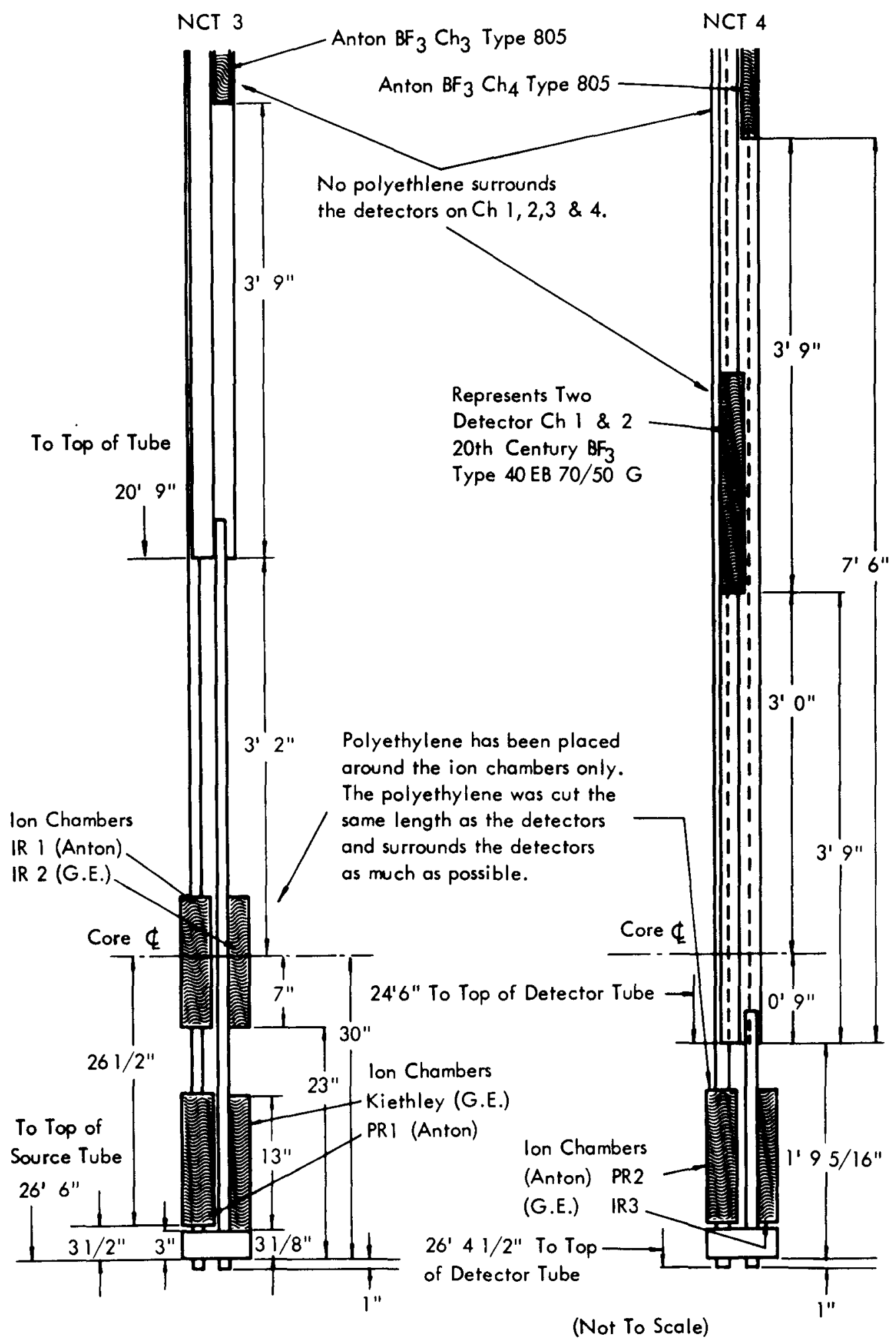

FIG. 5 TEMPORARY DETECTOR POSITIONS IN NEUTRON - COUNTER TUBES 3 AND 4 
TABLE I - NEUTRON DETECTOR CHARACTERISTICS

\begin{tabular}{|c|c|c|c|c|c|c|c|}
\hline \multirow[b]{2}{*}{ Type } & \multirow[b]{2}{*}{ Manufacturer } & \multirow[b]{2}{*}{ Catalog No. } & \multicolumn{4}{|c|}{ Dimensions, inches } & \multirow{2}{*}{$\begin{array}{l}\text { Published Thermal } \\
\text { Neutron Sensitivity }\end{array}$} \\
\hline & & & $\mathrm{A}$ & $\mathrm{B}$ & $\mathrm{C}$ & $\mathrm{D}$ & \\
\hline roportional & $\begin{array}{l}\text { Twentieth Century, } \\
\text { Ltd. }\end{array}$ & $40 \mathrm{~EB} 70 / 50 \mathrm{G}$ & 20 & 9 & 2 & 16 & $73 \mathrm{cps} / \mathrm{nv}$ \\
\hline $\begin{array}{l}\text { roportional } \\
\text { r }\end{array}$ & Reuter-Stokes & $\mathrm{RSN}-45 \mathrm{~A}$ & 22 & 11 & 2 & 20 & 52.5 \\
\hline $\begin{array}{l}\text { Proportional } \\
\text { ter }\end{array}$ & Anton & 805 & 10 & 5 & 1 & 8 & 4.5 \\
\hline $\begin{array}{l}\text { on Counter } \\
\text { nnector) }\end{array}$ & Westinghouse & $\mathrm{WX} 4420$ & 14 & 6 & $13 / 4$ & 10 & $0.56(550 \mathrm{~F})$ \\
\hline $\begin{array}{l}\text { on Counter } \\
\text { nnector) }\end{array}$ & Westinghouse & WX 4516 & 12 & $51 / 2$ & $31 / 16$ & 7 & $0.7 \quad(550 \mathrm{~F})$ \\
\hline nber & Anton (Lionel) & 813 & 13 & $51 / 4$ & $31 / 8$ & $71 / 2$ & $4.4 \times 10^{-14} \mathrm{amp} / \mathrm{nv}$ \\
\hline nber & Reuter-Stokes & $\mathrm{RSN}-36 \mathrm{~A}$ & $123 / 8$ & $51 / 2$ & $31 / 8$ & $71 / 4$ & $4 \times 10^{-14}$ \\
\hline ted Ion & Reuter-Stokes & $\mathrm{RSN}-15 \mathrm{~A}$ & $221 / 8$ & $91 / 2$ & $31 / 8+$ & $-1313 / 16$ & $-4 \times 10^{-14}$ \\
\hline
\end{tabular}

\begin{abstract}
Chamber
\end{abstract}
(1) Type used for source range of temporary startup instrumentation

(2) High sensitivity counters used for general survey in all NCT's

(3) Used to improve spatial resolution flux mapping in NCT's 2 and 4

(4) Used for flux mapping NCT's 2, 3, and 4 to obtain source range response

(5) Permanent plant source range detector

(6) Similar to originally proposed permanent plant intermediate and power range detectors

(7) Permanent plant power range detector

(8) Permanent plant intermediate range detector

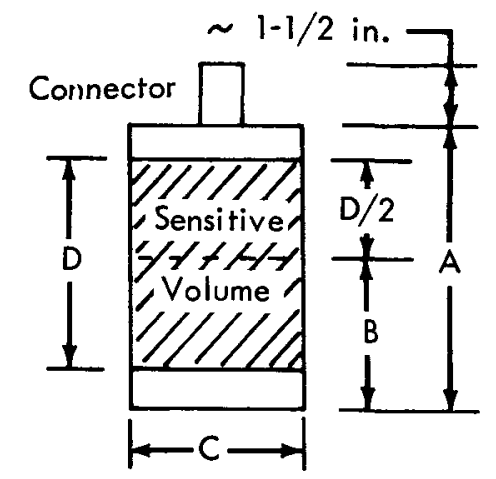




\section{EXPERIMENTAL PROCEDURE}

\section{A. DESCRIPTION OF THE TEST}

The test was logically divided into three parts: the first part was the measurement of the relative and absolute neutron detector responses in the NCT's; the second part was the determination of the shutdown power level as a function of the neutron source strength; and the third part was the measurement of the gamma radiation dose rates after shutdown in the NCT's. A brief description of the test procedure used for each measurement is given below. A detailed description can be found in Reference 2 .

\section{Measurement of Neutron Detector Responses}

Two different sets of neutron detector responses were measured in the test. Relative responses for the B-10 ( $n, a)$ and $U-235$ fission reactions were first obtained in the NCT's using the special test instrumentation and then the absolute responses of the permanent plant detectors were obtained in selected NCT's.

a. Relative Detector Responses - A general survey was made in all six NCT's of the relative boron-10 responses to the neutron flux as a function of position using the test instrumentation's high-sensitivity ReuterStokes $\mathrm{BF}_{3}$ proportional counter. The technique was to bring the reactor critical at a steady-state low-power level, place the $B F_{3}$ counter at the bottom of the NCT of interest, and record the count rate. The counter was then positioned at a number of additional elevations within the NCT and the new count rate data recorded. Detailed monitoring of the reactor power for reference purposes was obtained by recording the scaler output of the several source range channels of the temporary startup instrumentation system each time the count rate of the counter used in the traverse was recorded. For convenience, all the detector responses obtained were normalized to detector output per watt of reactor power. Therefore, the responses obtained using the test instrumentation were relative only in the sense that they did not directly give the absolute $B-10$ responses of the permanent plant instruments. The same mapping procedure was repeated for each of the six NCT's. However, the mapping of NCT's 3 and 4 was additionally complicated due to the fact that these tubes contained the temporary startup instrumentation. Therefore, a rather complex scheme was employed to expedite the flux mapping of NCT's 3 and 4 . First, to map NCT 4 the various electronic channels required for low power operation (see Section II. D)were redistributed among the detectors such that they were all located in NCT 3 . The detector rack was then removed from NCT 4, placed in a decay storage tank, and the mapping of NCT 4 proceeded as normal. Mapping of NCT 3 was 
accomplished by transferring the detectors required for operation from NCT 3 to NCT 4 and repeating this procedure. An absolute power calibration was maintained at all times by placing an additional detector in one of the empty neutron counter tubes (NCT 2) and calibrating it against the normal channels prior to the transfers described above. A detailed explanation of the procedure described above for mapping NCT's 3 and 4 is given in $\mathrm{Re}-$ ference 3 .

The high-sensitivity Reuter-Stokes $\mathrm{BF}_{3}$ proportional counters used for the general survey had sensitive volumes some 20 inches long. To find out whether these flux mappings were sensitive to the spatial resolution of the measurement, additional traverses were made with an Anton $\mathrm{BF}_{3}$ proportional counter which had a sensitive volume only 8 inches long in NCT's 2 and 4 . The mapping technique was identical to that described above for the Reuter-Stokes counters.

Although most of the permanent plant detectors are ion chambers which will contain boron, the source range detectors which are to be located in NCT 3 and perhaps NCT 4 are U-235 fission counters. Therefore, traverses were also made in NCT's 3 and 4 using a one-connector Westinghouse fission counter and employing the techniques described earlier. NCT 2 was also included in the fission counter traverses in order to obtain additional basic data for comparison with the absolute responses obtained later. In conjunction with the fission counter relative response measurements, an experiment was performed to determine the effect on detector sensitivity resulting from placing a moderating material around the detector. Successive layers of polyethylene were wrapped completely around the full length of the Westinghouse fission counters and the response was measured relative to that obtained with no moderator. This measurement was made 6 inches and 30 inches above the bottom of NCT's 2 and 4, respectively, in order to see whether the effect was strongly elevation-dependent.

Lastly, to aid in the interpretation of the measured responses, some of the earlier $\mathrm{B}-10$ and fission counter traverses were repeated with the detectors surrounded by a cadmium can. The ratio of these results to those obtained with the detectors bare provided the cadmium ratio, a useful spectral index. These traverses were made with the Westinghouse fission counter in NCT 4 and with the Anton BF3 proportional counters in NCT's 2 and 4 using a cadmium can open at the top (open cadmium can). The length and wall thickness of the cadmium can were 14-1/4 inches and $1 / 16$ inch, respectively. Additional traverses with an Anton $\mathrm{BF}_{3}$ proportional counter were made at a later date in NCT's 1 and 2 with a cadmium can somewhat larger than specified above and closed at the top except for a small opening for cable passage (closed cadmium can). These additional measurements were made to reduce the thermal neutron in-leakage into the counter and thus obtain a measure of the effect of such leakage on the previous open can traverses. In connection with the closed cadmim can measurements, the 
traverses with bare Anton $\mathrm{BF}_{3}$ counters were repeated in NCT's 1 and 2 for comparison purposes. This repetition was done at this later date to minimize artificial response differences between the bare and cadmium covered detectors arising from long-term effects such as electronic drift.

b. Absolute Detector Responses - After the relative B-10 ( $n, a)$ and $U-235$ fission responses were obtained in the counter tubes of interest using the test instrumentation, an absolute calibration of detector response versus reactor power was made for each type of detector to be used in the permanent plant instrumentation system. This included a one-connector Westinghouse fission counter similar, but not exactly identical, to the twoconnector Westinghouse fission counters to be used for the permanent plant source range channels and an Anton B-10-lined ion chamber similar to that to be used for both the permanent plant intermediate range and power range channels. These detectors are types 4 and 6 , respectively, in Table I. The absolute calibrations were all made in NCT 2 , and this NCT was included in all of the relative mappings made previously. This made it possible to relate all of the responses obtained in the relative flux mappings to the absolute responses of the permanent instruments. The measurements were made by individually placing each detector at a known elevation in NCT 2 and recording its output at a known power level. The data were then normalized to the detector output per watt of reactor power. Electronic conditions for the permanent-plant-type detectors were chosen to correspond to those planned for permanent plant operation. These conditions included the input impedance to the preamplifier, the amplifier gain, the high voltage level, and the discriminator level setting.

Formal calibration checks were also made at this time for most of the detectors used in the relative flux mappings. These data were not needed to determine the final placement of the permanent plant detectors but they did provide a convenient tool for checking the previous measurements.

Following the absolute calibration measurements described above, a preliminary evaluation was made of the performance of the Anton ion chambers to be used in the permanent plant instrumentation. The evaluation indicated that they would give unsatisfactory operation, mainly because of the failure of the insulation in the associated cable to provide a sufficiently high resistance between signal and ground. Because of this, the original concept of using compensated Anton B-10-lined ion chambers for both the intermediate and power range channels (with the power range detector compensation unconnected) was abandoned, and it was decided to replace these detectors with Reuter-Stokes compensated and uncompensated B-10-lined ion chambers for coverage in the intermediate and power ranges, respectively. A cross-calibration was therefore made between the Reuter-Stokes chambers and the Anton chambers to assure that their sensitivities were essentially the same since the position specifications for the permanent plant detectors had to be, of necessity, based on the more complete Anton ion chamber flux mapping results. 
A similar cross calibration was also made at a later date between a two-connector Westinghouse fission counter identical to those specified for the permanent plant instrumentation and the one-connector Westinghouse fission counter used in the initial absolute detector response measurements described above.

\section{Shutdown Power Level Determination}

One of the purposes of the test was to determine the neutron source strength required to produce $10 \mathrm{cps}$ at shutdown on the permanent source range channels. This was the minimum count rate specified for reactor startup. 1 Since all of the absolute detector responses obtained were normalized to detector output per watt of reactor power, the required neutron source strength could be found simply by determining the ratio of the source strength to shutdown power (S/P). This was done by measuring the shutdown power, using the source range channels of the temporary startup instrumentation, and making, at the same time, a careful determination of the decaying $\mathrm{Sb}-\mathrm{Be}$ source strength. The excess reactivity existing at this time was also noted since the shutdown count rate (source multiplication for a given source) is a function of the shutdown reactivity of the system. The determination made of $\mathrm{S} / \mathrm{P}$ was based on reactor and source conditions existing on October 15, 1963.

\section{Shutdown Gamma Dose Determination}

The gamma dose rates in the $\mathrm{NCT}^{\prime} \mathrm{s}$ during reactor operation were measured as part of the shield test program. The gamma dose rates in all six NCT's following reactor operation were measured in this test for use in the detector placement analysis in the following manner. The reactor was brought to criticality at a steady-state power level and operated for a fixed length of time. The power level chosen was high in relation to the power level at which the reactor had been operated during recent previous testing so that background gamma radiation from previous operation would be minimized during the measurements. Following scram, the detector portion of a disassembled Jordan Radgun mounted on a special carrier was lowered into the first NCT. The gamma dose rate and time after scram were recorded. The Ragdun was then repositioned at approximately one-foot intervals throughout most of the tube length and the corresponding dose rates and times after scram were recorded. This procedure was followed for all six NCT's. The temporary startup instrumentation was temporarily removed from NCT's 3 and 4 to allow passage of the Radgun. The removal of this instrumentation posed no hazard since the reactor was shut down and neutron detection was not required for the safety system. In addition to the spatial traverses described above, measurements were also made of the rate of decay of the gamma dose rates in NCT's 1 and 2 by making traverses at several subsequent times. The measurements of the gamma dose decay rate were required in order that a meaningful extrapolation could be made 
of the measured dose rates to those that would be obtained following longterm reactor operation. Temperature monitoring of the Radgun was accomplished through a thermocouple mounted on the carrier to assure that its $150 \mathrm{~F}$ operating limit was not exceeded.

The foregoing measurements were accomplished following two separate reactor runs. The nominal traverses of all six NCT's followed a power run of $149 \mathrm{kw}$ for 2.82 hours. The decay rate measurements followed a power run of $750 \mathrm{kw}$ for 1.25 hours.

\section{B. EXPERIMENTAL EQUIPMENT}

The principal experimental equipment required for the neutron and gamma response measurements in the NCT's consisted of the appropriate detectors, their associated electronics, the special carriages for detector mounting, the specially constructed cadmium cans, and the polyethylene moderator material. A brief description of each is given below.

Neutron Detectors - A listing of the neutron detectors pertinent to this experiment together with a brief listing of their characteristics is given in Table I. The table does not include the types used in the temporary startup instrumentation system except where noted.

Gamma Detector - The gamma dose rate mapping was done with a Jordan Radgun. This is a battery powered portable ionization chamber with a range of $.01 \mathrm{mr} / \mathrm{hr}$ to $10^{4} \mathrm{R} / \mathrm{hr}$. There are provisions for separating the chamber portion from the readout portion and connecting the two with a cable. This mode of operation was used in the present experiment to allow remote monitoring of the gamma level in the NCT's.

Detector Electronics - The electronics required to operate the de tectors and read out their responses generally consisted of standard off-theshelf items. A general listing of the equipment used is given in Table II. The specific values of the highvoltages supplied to the detectors, the amplifier gains, the discriminator settings, and the input impedances to the preamps used in the testing are not given in Table II. Instead, they are given later in conjunction with the results of the runs, since their values varied somewhat throughout the test.

Carriages - Wire frame carriages made of stainless steel were constructed in such a manner that any given detector could be positioned near the center of the neutron counter tube. A steel measuring tape was attached to the carriage to provide a means of determining elevation and to support most of the detector weight. The carriage also provided a convenient framework for the attachment of a thermocouple when the ambient temperature was expected to be near the upper operating temperature limit of the detector. 
TABLE II - NEUTRON DETECTOR ELECTRONICS

$\underline{\text { Detector }} \underline{\text { Preamplifier } \quad \underline{\text { Amplifier }} \text { Readout }}$

Proportional Stromberg-Carlson Hamner N-30l RIDL 49-51 Scaler Counters (Modified)

Fission

Stromberg-Carlson

Hamner M-302 RIDL 49-51 Scaler

Counters

(Modified)

Ion Chambers

$---$

(Keithly Micromicroammeter)
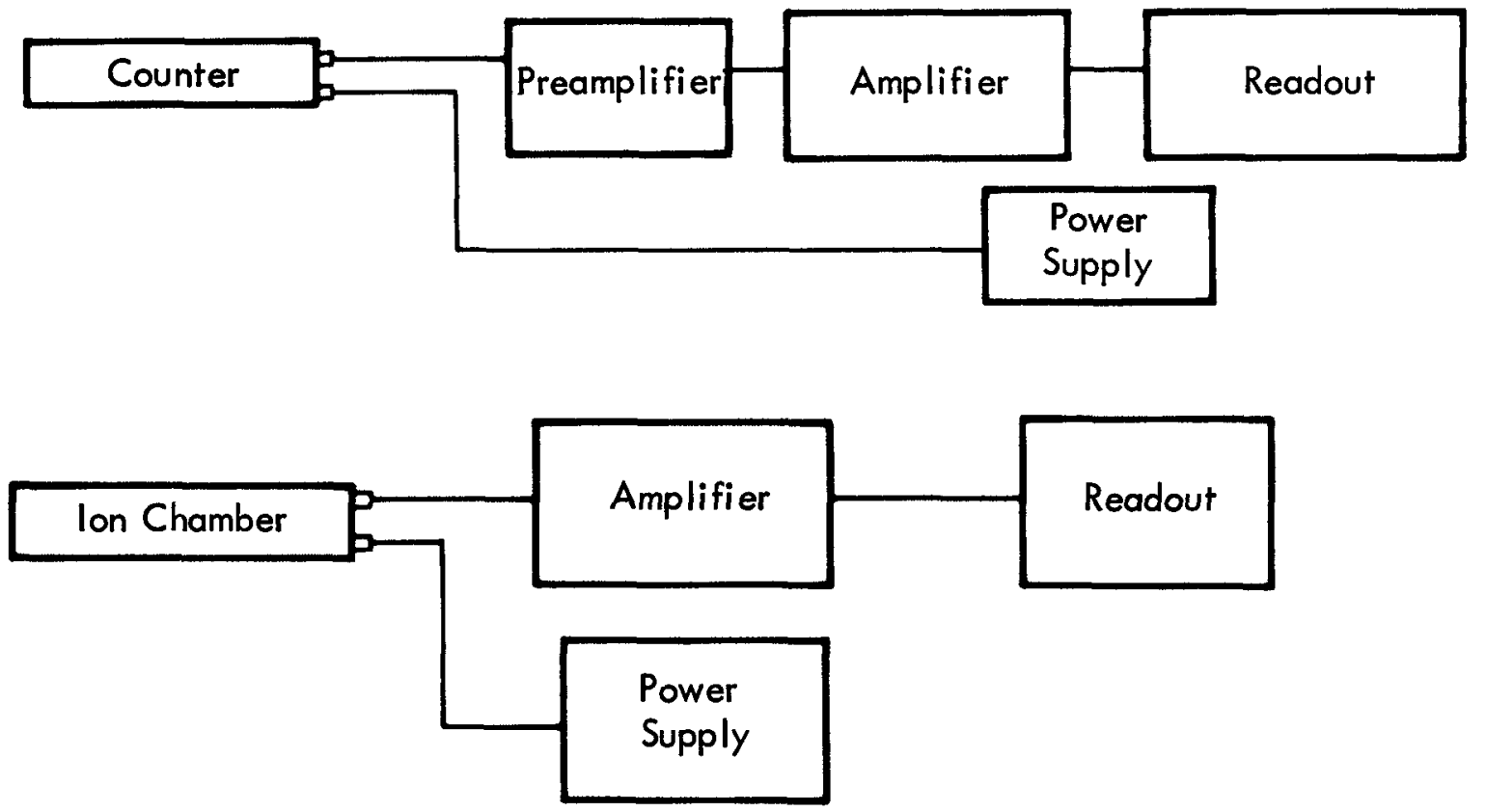

Cadmium Cans - To obtain neutron spectrum information, some detectors were enclosed in cadmium cans. The nominal can was in the form of a hollow cylinder 14-1/4 inches long with 1/16-inch wall thickness. The cylinder was closed at the bottom, but completely open at the top to allow cable passage. Later measurements were made with a somewhat longer can with the open end partially closed, allowing minimal space for cable passage.

\section{REACTOR PLANT CONDITIONS}

The experiments took place over a long period of time so that the reactor plant conditions changed somewhat during the course of the experiment. However, the majority of the neutron response measurements took place during November and December of 1963 when the retractable source was located in safety rod position 5. For this condition the core loading 
was 98 full core subassemblies and one core shim subassembly, providing an excess reactivity of about 38 cents with the primary sodium temperature at $517 \mathrm{~F}$. Though the core configuration did vary slightly for later measurements, the primary sodium temperature was maintained near $517 \mathrm{~F}$ for all neutron response measurements, since the external neutron detector responses depend on the system temperatures.

Most of the neutron response measurements were performed at power levels between 100 watts and 1 kilowatt. Gamma ray measurements were performed at powers between $100 \mathrm{kw}$ and $1 \mathrm{Mw}$. 
- 
IV. EXPERIMENTAL RESULTS AND DATA REDUCTION

\section{A. NEUTRON DETECTOR RESPONSE MEASUREMENTS}

The results of the relative and absolute neutron detector response measurements in the NCT's are presented below. The data have been reduced to a form suitable for use in determining the final positions of the permanent plant detectors. A correction factor for calculating the effective shadowed response of the intermediate range ion chambers is also given.

\section{Relative Detector Responses}

The raw data obtained in the relative detector response mappings consisted of the response of a given test detector at a given elevation in a given NCT and the output of one or more of the temporary startup instrumentation detectors being used for monitoring the reactor power for reference purposes. Use of the latter data and the reactor power calibration data gave the reactor power. The desired normalized detector output was then obtained by dividing the output of the detector by the reactor power.

The detector elevations in the NCT's were originally specified in the test by measuring the distance between the bottom of the NCT and the bottom of the detector. However, because the sensitive volumes of the various detectors varied from several inches to almost 2 feet in length, it was later decided that it would be more meaningful to assign the detector response obtained to a position corresponding to the midplane of its sensitive volume rather than to the bottom of the detector. The translations of the position measurements from the bottom of the detectors to their sensitive volume midplanes were made using the appropriate detector dimensions given in Table $\mathrm{I}$.

The results of the general traverses made with the Reuter-Stokes $\mathrm{BF}_{3}$ proportional counter in all six $\mathrm{NCT}^{\prime} \mathrm{s}$ are given in Figure 6 . The results of the traverses made with the shorter Anton $B F_{3}$ proportional counter in NCT's 2 and 4 are given in Figure 7. Also included in Figure 7 are the same traverses made with the detector inside the open cadmium can. Figure 8 gives the results of the additional traverses made at a later date in NCT's 1 and 2 with the Anton $\mathrm{BF}_{3}$ counter enclosed inside the closed cadmium can and it gives the results of the bare traverses made at this time for comparison purposes. The results of the traverses made with the bare $\mathrm{U}-235$ Westinghouse fission counter in NCT's 2, 3, and 4 are given in Figure 9 , as are the results of the fission counter traverse made in NCT 4 with the detector inside the open cadmium can. The pertinent electronic settings and input impedances to the preamplifiers for all of the above traverses are also given in the figures. 


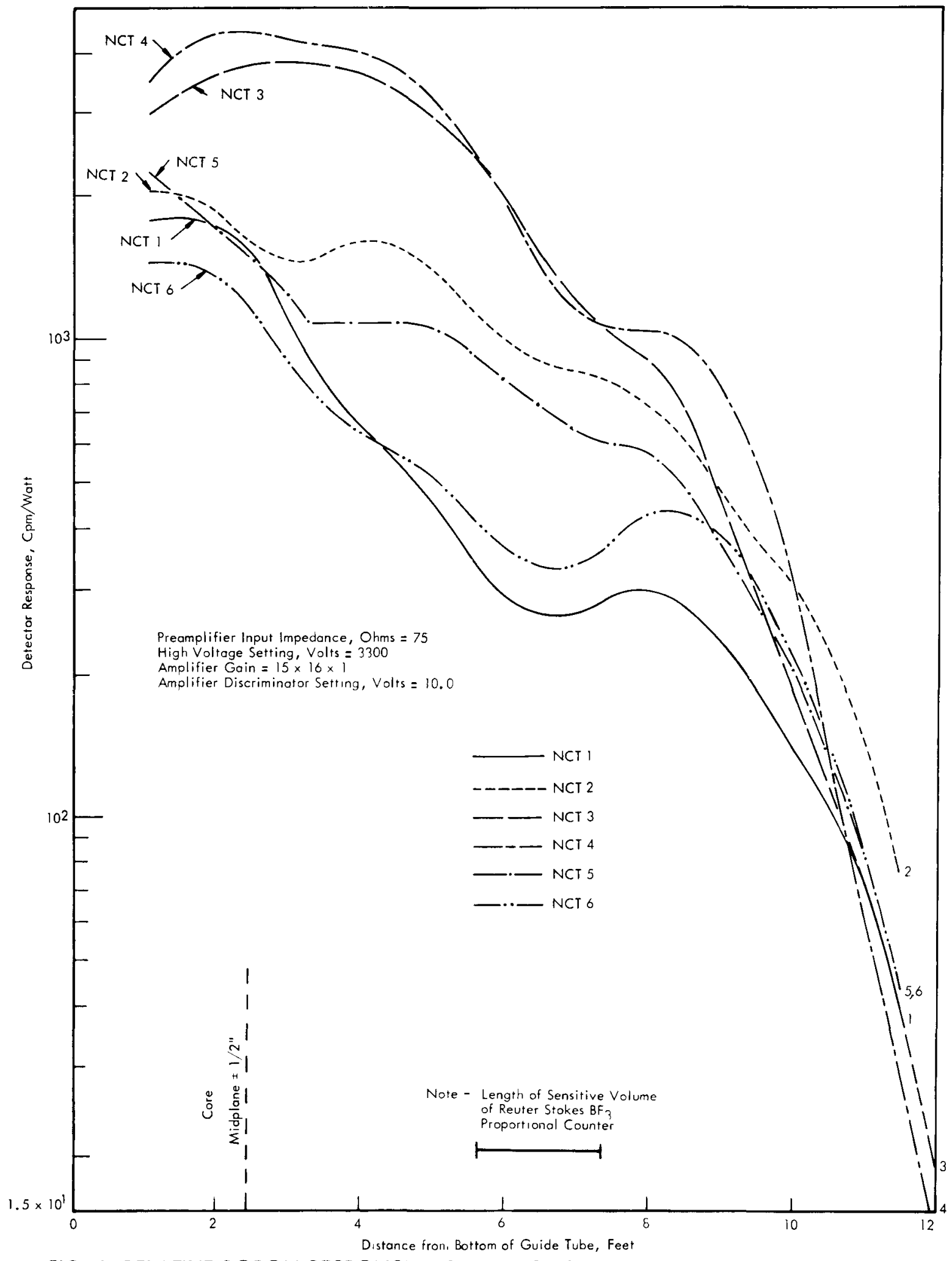

FIG. 6 RELATIVE BORON RESPONSE DISTRIBUTIONS IN THE NEUTRON.COUNTER TUBES USING A REUTER-STOKES BF 3 PROPORTIONAL COUNTER 


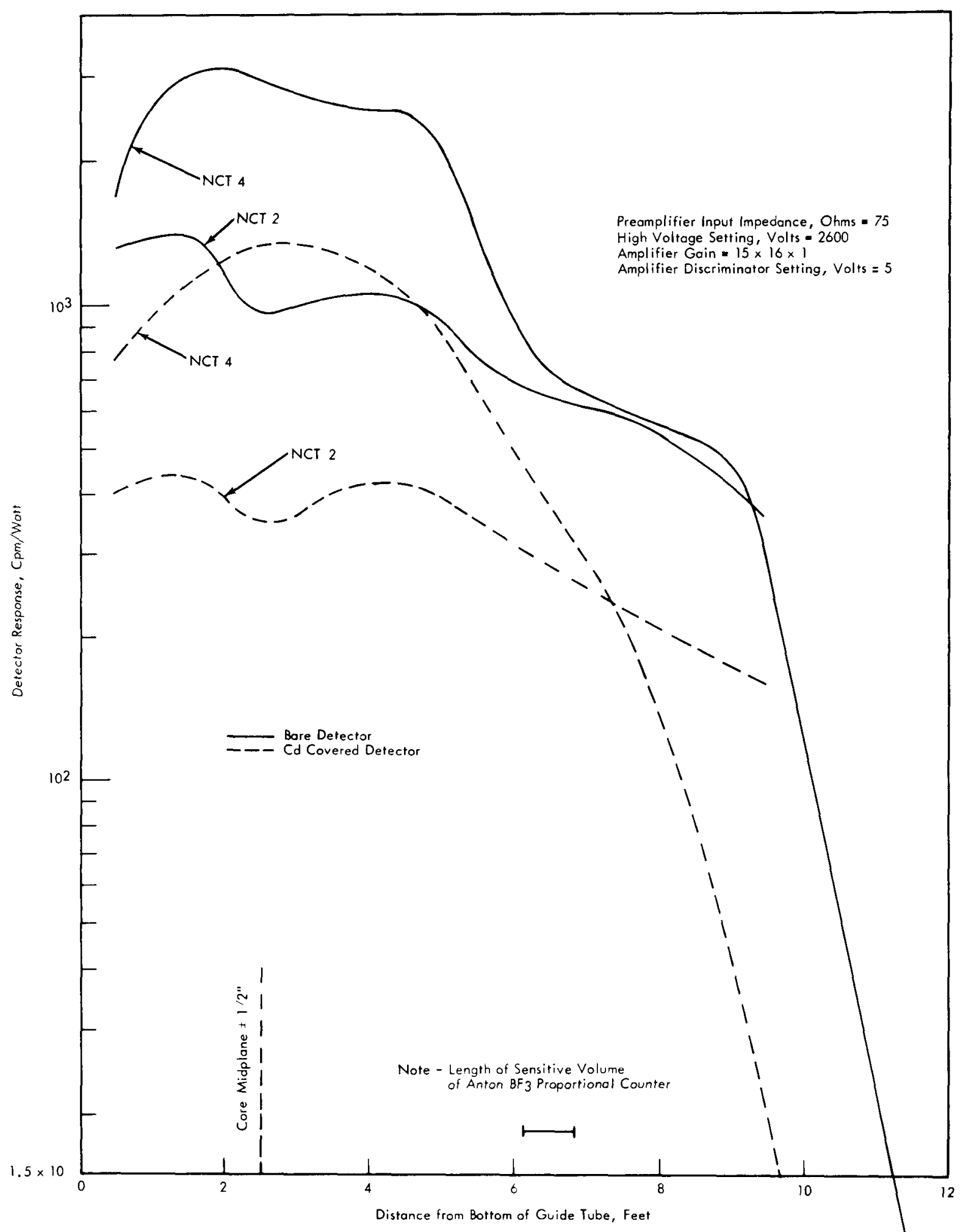

FIG. 7 RELATIVE BORON RESPONSE DISTRIBUTIONS IN THE NEUTRON-COUNTER TUBES 2 AND 4 USING AN ANTON BF 3 PROPORTIONAL COUNTER BARE AND INSIDE AN OPEN CADMIUM CAN 




FIG. 8 RELATIVE BORON RESPONCE DISTRIBUTIONS IN NEUTRON - COUNTER TUBES 1 AND 2 USING AN ANTON BF ${ }_{3}$, PROPORTIONAL COUNTER BARE AND INSIDE A CLOSED CADMIUM CAN 


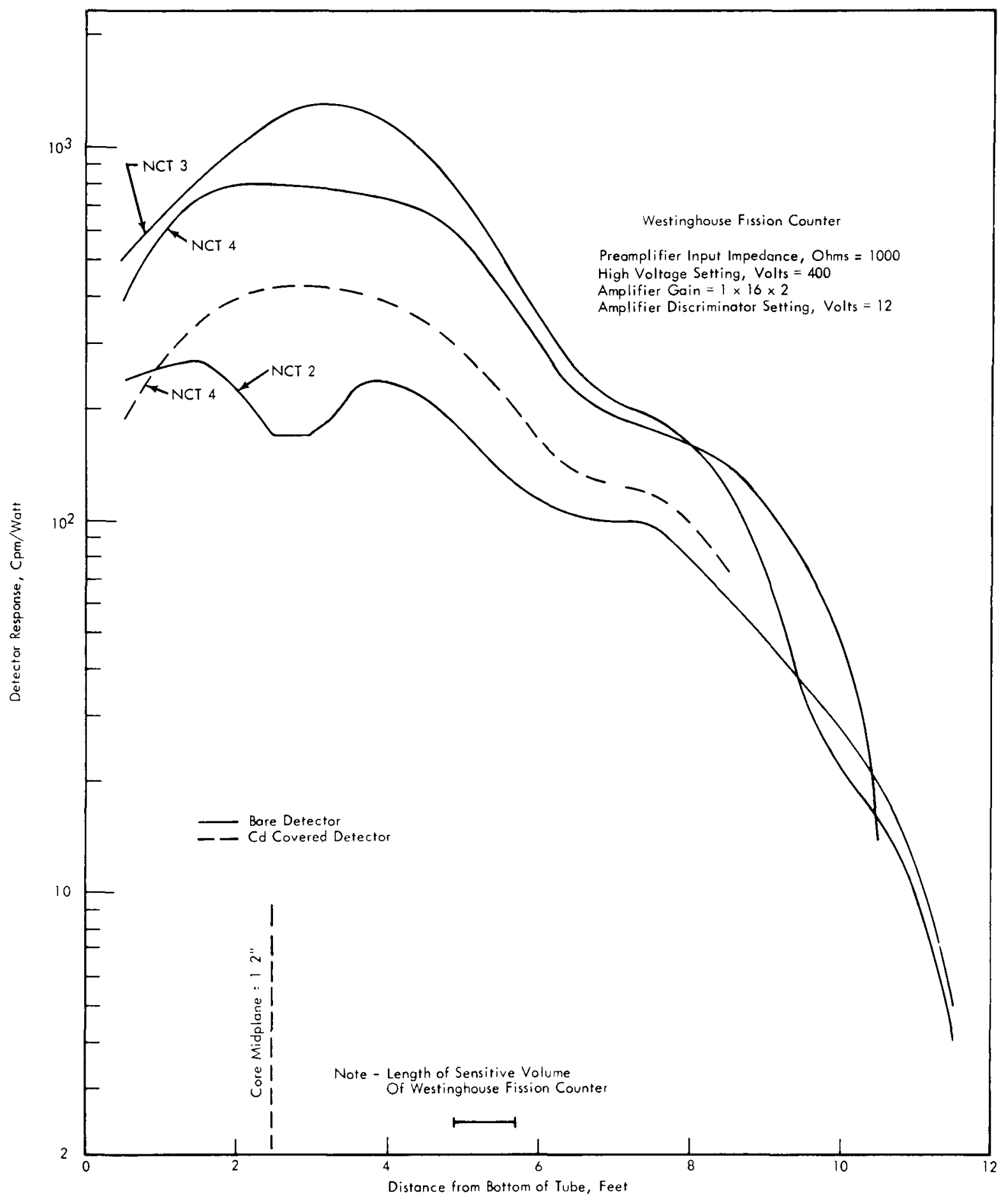

FIG. 9 RELATIVE U.235 FISSION RESPONSE DISTRIBUTIONS IN NEUTRON-COUNTER TUBES 2, 3, AND 4 USING A WESTINGHOUSE FISSION COUNTER BARE AND INSIDE AN OPEN CADMIUM CAN 
The fission counter measurements made in NCT's 2 and 4 which studied the effect of the polyethylene moderator were also made in this part of the test, but the results are not reported here. The results of these measurements and also the cadmium ratio measurements are discussed separately in detail in Section IV. B.

The position specifications in Figures 6 through 9 are given in terms of the distance, L, from the bottom of the neutron counter tube to the midplane of the sensitive volume of the detector. As mentioned, the positions were specified in this way in order to eliminate differences arising from different detector geometries. It was also of interest to know the absolute detector elevations above sea level so that the data could be used in conjunction with the reactor construction drawings which have all elevations specified in this manner. To translate the position specifications given in Figures 6 through 9 to absolute elevations above sea level, it is necessary to know the elevation above sea level of the bottom of each of the NCT's and the angle they make with the vertical, since the NCT's are not absolutely perpendicular. This information is given in Table III. As seen, these are not the same for each NCT. However, using the average value of the NCT angle from the vertical, $\vec{\theta}$, and the average elevation of the bottom of the NCT's above sea level, $\overline{\mathrm{H}}$, the absolute detector elevation, $\mathrm{E}$, above sea level becomes,

$$
\begin{aligned}
E & =\bar{H}+L \operatorname{Cos} \bar{\theta} \\
& =562.33+0.9936 L
\end{aligned}
$$

\section{TABLE III - ELEVATION AND ANGLE OF NEUTRON COUNTER TUBES}

$\begin{array}{lcc}\text { Neutron Counter Tube } & \begin{array}{c}\text { Elevation } \\ \text { (feet above sea level) }\end{array} & \begin{array}{c}\text { Angle } \\ \text { (degrees from vertical) }\end{array}\end{array}$

1
2
3
4
5
6

562.36

7.2

$2 \quad 562.29$

562.36

6.3

562.33

6.0

5

562.30

5.4

6

562.34

6.4

7. 7

Average

562.33

6.5

Maximum Deviation

from Average

0.04

1.2

* Elevation of Core Midplane: 564.77 feet 
The error incurred by using the average values of $\theta$ and $H$ in this formula is less than \pm 0.1 feet for traverses of less than 20 feet from the bottom of any neutron counter tube.

\section{Absolute Detector Responses}

Two sets of absolute detector response measurements were made in the test. An absolute calibration of detector response versus reactor power was first made for all of the permanent plant detectors, and most of the test instrumentation detectors, listed in Table I. This initial set of calibration measurements did not include, however, the calibration of the twoconnector Westinghouse fission counter and the Reuter-Stokes ion chamber detector types specified for use in the revised permanent plant instrumentation system since they were either not available or else nonoperational at this time. (See Section III. Alb.) They were therefore calibrated in the second set of cross-calibration measurements.

The purpose of the absolute calibrations was twofold. First, a calibration of the two detector types to be used in the permanent plant instrumentation system was required to relate the relative response data to the permanent instruments and to allow the final placement of these detectors to be determined. Second, a formal calibration of the detectors used in the mapping provided a convenient tool for checking the previous measurements. All of the detectors were calibrated at the bottom of NCT 2 except for the high sensitivity Reuter-Stokes $\mathrm{BF}_{3}$ detectors which were elevated somewhat in NCT 2, in order to decrease the count rate and prevent saturation. The raw data obtained in the first set of absolute calibrations was the response of a given detector and the output of the three temporary startup instrumentation system channels used for power monitoring. The raw data from the first set of measurements are given in Table IV.

To convert the raw data to the desired normalized output of detector response per watt of reactor power, the output of the three power monitoring channels was converted to reactor power using the power calibration data; the detector responses were then divided by the power. When there was a discrepancy among the three power monitoring channels, the best value was chosen based on examination of the data and the previous stability experience of the channels. When there was more than one count rate taken per channel, the average value was usually used. The resulting normalized detector absolute calibration data a re given in Table V. It will be noted that detector responses are given at two different positions in NCT 2 in Table V. In order to facilitate intercomparison among the counters, the calibration data obtained at the bottom of NCT 2 were all extrapolated to a common elevation in the neutron counter tube. The position chosen was such that the midplane of the sensitive volume of each detector was located at the elevation of the core midplane. The extrapolation to this position was accomplished by using the relative response distribution curves for NCT 2 
TABLE IV - ABSOLUTE DETECTOR CALIBRATION DATA OBTAINED AT BOTTOM OF NCT 2 (OCTOBER 31, 1963)

\begin{tabular}{|c|c|c|c|c|c|c|c|c|c|c|}
\hline & \multirow[b]{2}{*}{ Detector } & \multirow[b]{2}{*}{$\begin{array}{c}\text { Preamplifier, } \\
\text { Ohms Input }\end{array}$} & \multirow[b]{2}{*}{$\begin{array}{c}\text { Hamner } \\
\text { Amplifier } \\
\text { Gain } \\
\end{array}$} & \multirow[b]{2}{*}{$\begin{array}{c}\text { High } \\
\text { Voltage, } \\
\text { Volts } \\
\end{array}$} & \multirow{2}{*}{$\begin{array}{c}\text { Hamner } \\
\text { Amplifier } \\
\text { Discriminator, } \\
\text { Volts } \\
\end{array}$} & \multirow[b]{2}{*}{ Time } & \multirow[b]{2}{*}{$\begin{array}{c}\text { Detector } \\
\text { Output, cpm } \\
\text { (Channel A) }\end{array}$} & \multicolumn{3}{|c|}{ Power Monitors } \\
\hline & & & & & & & & $\begin{array}{c}\text { Source } \\
\text { Range 1, } \\
\text { cpm }\end{array}$ & $\begin{array}{c}\text { Source } \\
\text { Range 2, } \\
\text { cpm }\end{array}$ & $\begin{array}{c}\text { Keithley, } \\
\text { amps }\end{array}$ \\
\hline 1. & $\begin{array}{l}\text { Westinghouse } \\
\text { Fission Counter } \\
\text { (one-connector) }\end{array}$ & 1000 & $1 \times 16 \times 2$ & 400 & 12 & $\begin{array}{l}1347 \\
1349 \\
1350 \\
1351\end{array}$ & $\begin{array}{l}133,496 \\
145,068\end{array}$ & $\begin{array}{l}761,427 \\
764,018 \\
765,327 \\
764,444\end{array}$ & $\begin{array}{l}812,775 \\
812,492\end{array}$ & $\begin{array}{l}.33 \times 10^{-8} \\
.33 \times 10^{-8}\end{array}$ \\
\hline 2 . & Anton Ion Chamber & & & 800 & & 1410 & & 763,814 & 810,096 & $.195 \times 10^{-9^{(1)}}$ \\
\hline 3. & $\begin{array}{l}\text { Reuter-Stokes } \\
\mathrm{BF}_{3} \text { Proportional } \\
\text { Counter }(2)\end{array}$ & 75 & $15 \times 16 \times 1$ & 3300 & 10 & $\begin{array}{l}1432 \\
1433\end{array}$ & $\begin{array}{l}598,713 \\
596,573\end{array}$ & $\begin{array}{l}750,538 \\
749,071\end{array}$ & $\begin{array}{l}793,355 \\
793,057\end{array}$ & $.325 \times 10^{-9}$ \\
\hline 4. & $\begin{array}{l}\text { Anton } \mathrm{BF}_{3} \\
\text { Proportional } \\
\text { Counter }\end{array}$ & 75 & $15 \times 16 \times 1$ & 2600 & 5 & $\begin{array}{l}1453 \\
1454 \\
1505 \\
1508\end{array}$ & $\begin{array}{l}578,543 \\
587,698 \\
156,344 \\
154,387\end{array}$ & $\begin{array}{l}750,968 \\
751,829 \\
199,385 \\
196,529\end{array}$ & $\begin{array}{l}794,996 \\
794,617 \\
210,364 \\
207,717\end{array}$ & $\begin{array}{l}.325 \times 10^{-8} \\
.805 \times 10^{-9}\end{array}$ \\
\hline 5. & $\begin{array}{l}20^{\text {th }} \text { Century } \mathrm{BF}_{3} \\
\text { Proportional } \\
\text { Counter }(3)\end{array}$ & 75 & $15 \times 8 \times 1.5$ & 4700 & 6.3 & $\begin{array}{l}1538 \\
1539\end{array}$ & $\begin{array}{l}1,640,760 \\
1,653,230\end{array}$ & $\begin{array}{l}191,053 \\
191,767\end{array}$ & $\begin{array}{l}201,700 \\
201,772\end{array}$ & $.77 \times 10^{-9}$ \\
\hline 6. & $\begin{array}{l}\text { Reuter-Stokes } \\
\mathrm{BF}_{3} \text { Proportional } \\
\text { Counter }(4)\end{array}$ & 1000 & $1 \times 16 \times 2$ & 3100 & 12 & $\begin{array}{l}1559 \\
1600\end{array}$ & $\begin{array}{l}1,089,871 \\
1,084,328\end{array}$ & $\begin{array}{l}194,857 \\
195,304\end{array}$ & $\begin{array}{l}205,025 \\
205,772\end{array}$ & $.79 \times 10^{-9}$ \\
\hline 7. & $\begin{array}{l}\text { Reuter-Stokes } \\
\mathrm{BF}_{3} \text { Propor tional } \\
\text { Counter }(5)\end{array}$ & 1000 & $1 \times 16 \times 2$ & 3100 & 12 & $\begin{array}{l}1607 \\
1609\end{array}$ & $\begin{array}{l}1,012,535 \\
1,006,324\end{array}$ & $\begin{array}{l}194,179 \\
193,471\end{array}$ & $\begin{array}{l}205,237 \\
204,390\end{array}$ & $.78 \times 10^{-9}$ \\
\hline
\end{tabular}

(1) Keithley channel transferred to Anton ion chamber for this one run.

(2) Electronics chosen to correspond to those used for traverse in Figure 6 .

(3) Electronics chosen to mock up conditions of source range channel for startup instrumentation.

(4) Bottom of detector located 6 feet above bottom of NCT 2. Electronics optimized.

(5) One of a cluster of 3 identical detectors located 6 feet above bottom of NCT 2 . Electronics optimized. 
TABLE V - ABSOLUTE DETECTOR RESPONSE IN NCT $2^{(1)}$

\begin{tabular}{|c|c|c|c|}
\hline Detector & $\begin{array}{l}\text { Reactor } \\
\text { Power, } \\
\text { watts } \\
\end{array}$ & $\begin{array}{l}\text { Response at } \\
\text { Position of } \\
\text { Measurement, } \\
\text { cpm/watt } \\
\end{array}$ & $\begin{array}{c}\text { Response Scalec } \\
\text { Core Midplan } \\
\text { Elevation } \\
\mathrm{cpm} / \text { watt } \\
\end{array}$ \\
\hline $\begin{array}{l}\text { inghouse } \\
\text { on Counter } \\
\text { connector) }\end{array}$ & 564 & 247 & 175 \\
\hline Ion Chamber & 568 & $\begin{array}{r}0.343 \times 10^{-12} \\
(\mathrm{amps} / \text { watt) }\end{array}$ & $\begin{array}{r}0.249 \times 10^{-12} \\
\text { (amps/watt) }\end{array}$ \\
\hline
\end{tabular}

3. Reuter-Stokes $\mathrm{BF}_{3}$

Proportional Counter (2)

553

850

1570

4. Anton $\mathrm{BF}_{3}$

Proportional Counter

146

1065

774

5. 20th Century BF3

Proportional Counter (3)

142

11599

9073

6. Reuter-Stokes $\mathrm{BF}_{3}$

Proportional Counter(4) 144

7549

13943

7. Reuter-Stokes $\mathrm{BF}_{3}$

Proportional Counter (5)

142

7123

13178

(1) Detector measurement numbers correspond to those of Table IV.

(2)-(5) See footnotes with corresponding numbers in Table IV.

given in Figures 6 through 8. Figures 6 and 7 were used for the boron detector extrapolations and Figure 8 was used for the fission counter extrapolations.

Later, additional absolute calibration measurements were made for the two-connector Westinghouse fission counter and the Reuter-Stokes B-10-lined ion chamber (the actual permanent plant detectors finally decided on) when these detectors were available and operational. The results of this second set of measurements indicated that these detectors were similar in response characteristics to their earlier counterparts, $i . e .$, the one-connector Westinghouse fission counter and the Anton B-10-lined ion chamber. It was found that any discrepancies which did exist could be compensated 
for by making gain adjustments in the permanent plant amplifiers. Thus, although all the analysis leading to permanent plant detector placement was based on the first set of absolute calibration measurements, the results are equally valid for the revised permanent plant detectors. For this reason, all late $r$ references to the permanent plant instrumentation will refer just to the one-connector Westinghouse fission chamber and the Anton B-10-lined ion chambers.

3. Shadowed Response of Permanent Plant Intermediate Range Ion Chambers

Analysis of the neutron detector response data and gamma ray dose rate data in the NCT's (see Section V. A 2a) indicated that the three permanent plant intermediate range ion chambers should all be placed at the position of maximum sensitivity in their respective counter tubes (NCT's 2 and 5). Furthermore, it was decided that because of the design of the detectors and their mounting racks, the two detectors to be located in one neutron counter tube would be placed side by side at this position, thus causing a slight shadowing effect of one detector on the other. A reduction in absolute response of 10 percent was measured for this effect. This is a conservative value. It is based on a comparison of the measured responses of the shadowed and unshadowed Reuter-Stokes $\mathrm{BF}_{3}$ proportional counters, shown in Items 6 and 7 of Tables IV and V.

\section{Power Calibration Data}

The measurements of the detector responses in the test required that the reactor power be known. The reactor power was monitored using the two source range channels, and one intermediate range Keithley channel of the temporary startup instrumentation (Section II. D). Calibration of these detectors against reactor power had been done early in the nuclear test program. 4 However, subsequent revisions in the channel electronics, detector types, detector positions, and moderator geometry within NCT's 3 and 4 during this test resulted in corresponding changes in the power calibration. Therefore, since the neutron counter tube flux mapping experiments spanned a considerable length of time, careful attention was paid to variations in the power calibrations of the temporary startup instrumentation during the test.

The power calibrations that existed during two phases of the test are given in Table VI. The phases given are: (1) the phase when the (S/P) shutdown power level determinations were being made (October 10, 1963), and (2) the phase when the absolute detector response measurements were being made at the bottom of NCT 2 (October 31, 1963). 
TABLE VI - REACTOR POWER CALIBRATION DATA FOR TEMPORARY STARTUP INSTR UMENTATION

(Valid October 3, 1963 to October 22, 1963)

Channel

Source Range 1 Source Range 2 Keithley

\section{Channel}

Source Range 1 Source Range 2 Keithley
Scaler, cpm/watt Micromicroammeter, amp/watt

3811

4221

(Valid October 23 to November 21, 1963)

Scaler, cpm/watt Micromicroammeter, amp/watt

1337

1433

$5.59 \times 10^{-12}$

Primary System Temperature@ 517 F

Calibration powers are in the range 100-250 watts.

B. SUPPLEMENTAL NEUTRON DETECTOR RESPONSE MEASUREMENTS

Concurrent with the relative detector response measurements in the neutron counter tubes, cadmium ratio measurements were made to obtain a spectral index for the flux at the counter tubes, and polyethylene moderator measurements were made to determine the effect of moderator materials on detector sensitivity. The results of these measurements are given below.

\section{Cadmium Ratio Measurements}

The cadmium ratio was obtained by dividing a given ba re detector response by its response obtained under the same conditions but with the detector surrounded by cadmium. This ratio provides a spectral index of the neutron flux since it provides the ratio of the reaction rate due to thermal neutrons $(<0.4 \mathrm{ev})$ compared to that due to epithermal neutrons, i. e. ,

$$
R_{t} / R_{e}=C R-1
$$

where

$$
\begin{aligned}
& \mathrm{R}_{\mathrm{t}}=\text { thermal neutron reaction rate } \\
& \mathrm{R}_{\mathrm{e}}=\text { epithermal neutron reaction rate } \\
& \mathrm{C} \text { = cadmium ratio. }
\end{aligned}
$$


Cadmium ratio data were initially taken using boron-10-loaded counters in NCT's 2 and 4 and a U-235 fission counter in NCT 4 (Section III. Ala). These original experiments were performed using a cadmium cover in the form of a can completely open at one end. The results of the resulting flux mappings are shown in Figures 7 and 9, respectively.

Later it was realized that if the thermal neutron flux were quite large relative to the total flux, even low thermal neutron leakage through the open top of the can might have had an appreciable effect on the counter responses and the resulting cadmium ratios obtained in these measurements. Therefore, to minimize this effect, additional B-10 traverses in NCT's 1 and 2 were made using a longer cadmium can with the top crimped in, thus allowing a hole at the top just large enough for cable passage. The measurements with this closed cadmium can were made at more frequent intervals of elevation than those in the original experiments and were extended some 10 feet further up the tubes. The results of the mappings are shown in Figure 8. Preliminary analysis of the data indicated that use of the closed cadmium can increased the measured cadmium ratios by about 20 percent near the tube bottom. Because these later measurements were clearly more accurate, only the cadmium ratios for the closed can experiments were analyzed in detail. The resulting cadmium ratios are shown in Figure 10 .

The cadmium ratios in Figure 10 are given as a function of elevation above sea level to facilitate a correlation between their values and the nearby shielding geometry; Equation 1 was used to make the elevation translation. Drawings of the shielding in the vicinity of NCT's 1 and 2 are given in Figures 11 and 12 . These are scale drawings, so the actual thicknesses of the various shield materials can be taken directly from the figures. The term "void" has been used in the figures to refer to areas where no shielding is present, although the areas may not necessarily be a real void. (Insulation, gaps, bellows, cable trays, etc., are all considered to be voids.) For convenience, the total void existing between the reactor vessel and neutron counter tube at any particular elevation has been shown as being located next to the counter tube in the figures. In actuality, however, the total void is in most cases made up of a number of smaller voids, none of which are necessarily located next to the counter tube.

\section{Polyethylene Moderator Measurements}

To investigate possible means of increasing the sensitivity of the permanent plant source range fission counter channels, successive layers of polyethylene were wrapped around a one-connector Westinghouse fission counter and the response was measured relative to that obtained with no moderator. The results of the measurements, made 6 inches and 30 inches above the bottom of NCT's 4 and 2, respectively, are shown in Figure 13. 


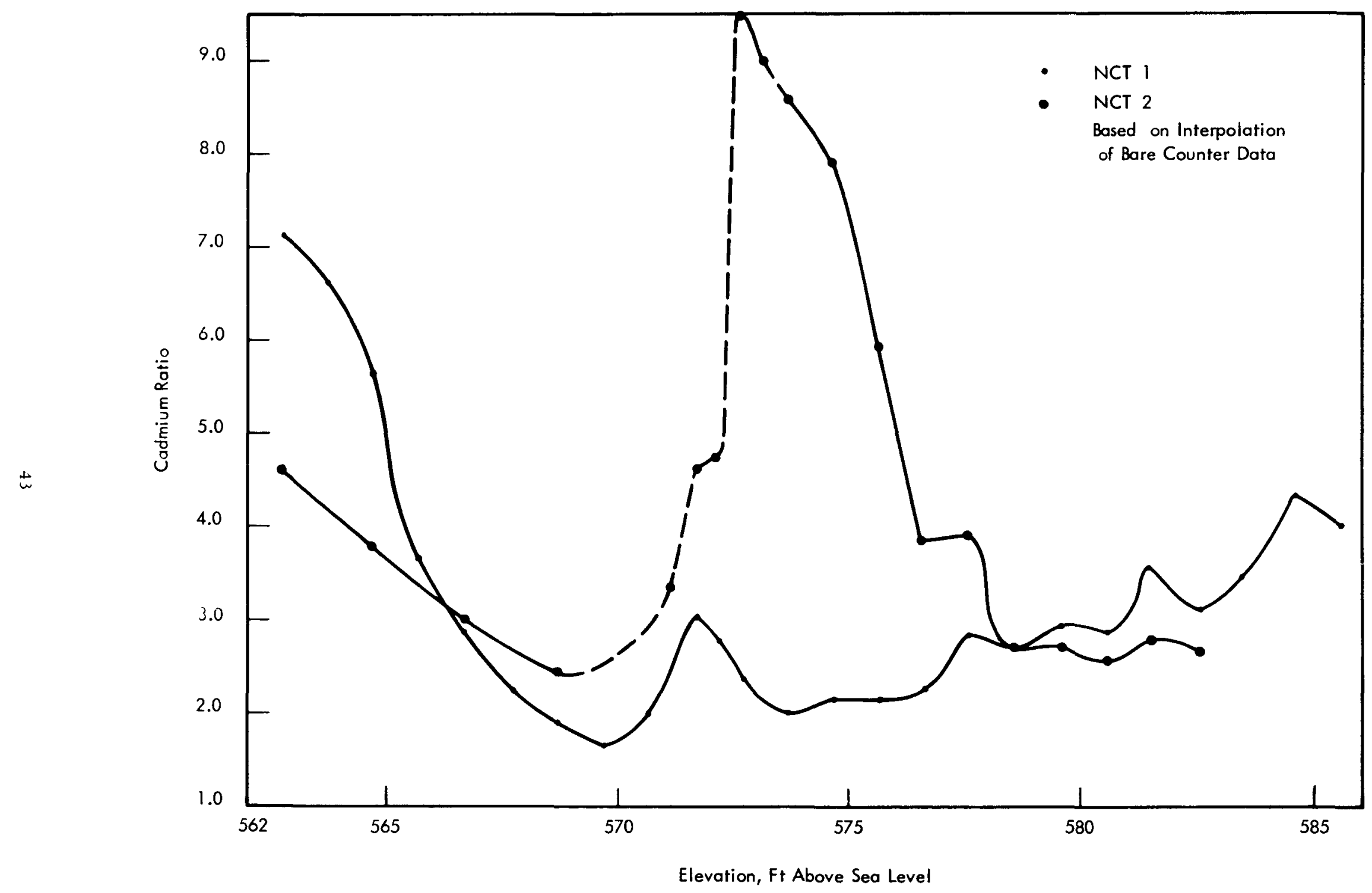

FIG. 10 CADMIUM RATIOS IN NEUTRON - COUNTER TUBES 1 AND 2 

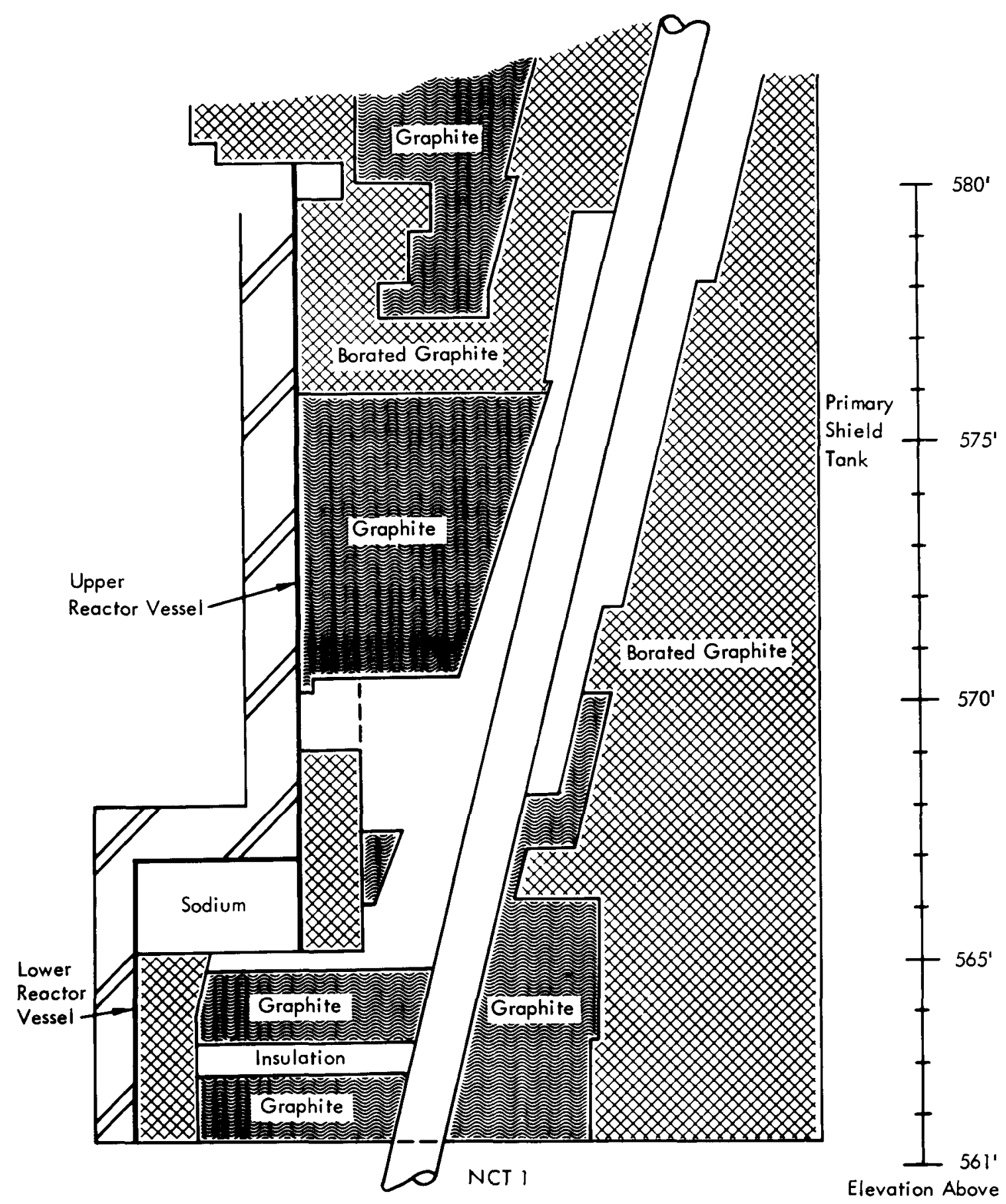

Elevation Above Sea Level

FIG. 11 SHIELD STRUCTURE NEAR NEUTRON - COUNTER TUBE 1 


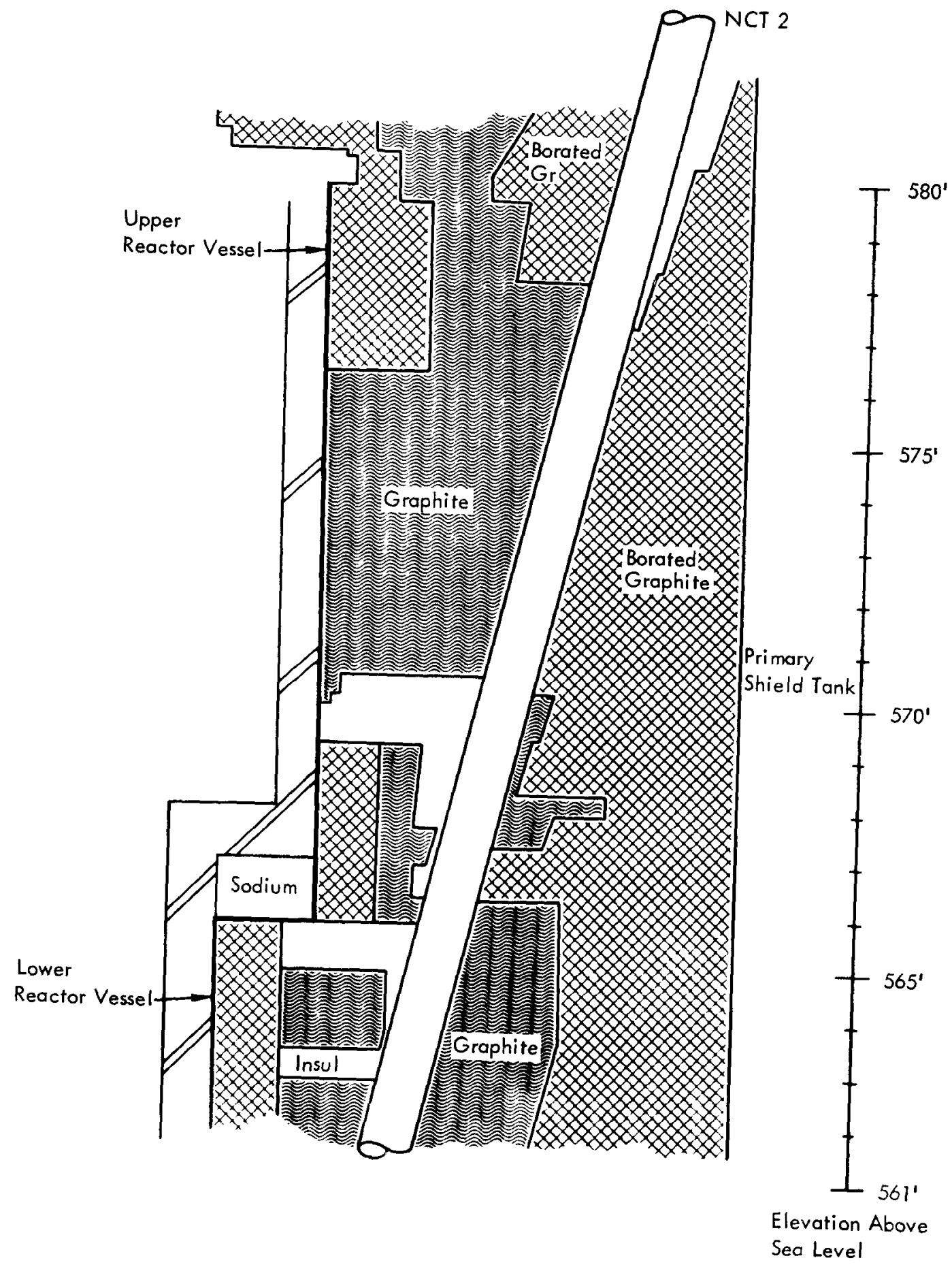

FIG. 12 SHIELD STRUCTURE NEAR NEUTRON - COUNTER TUBE 2 


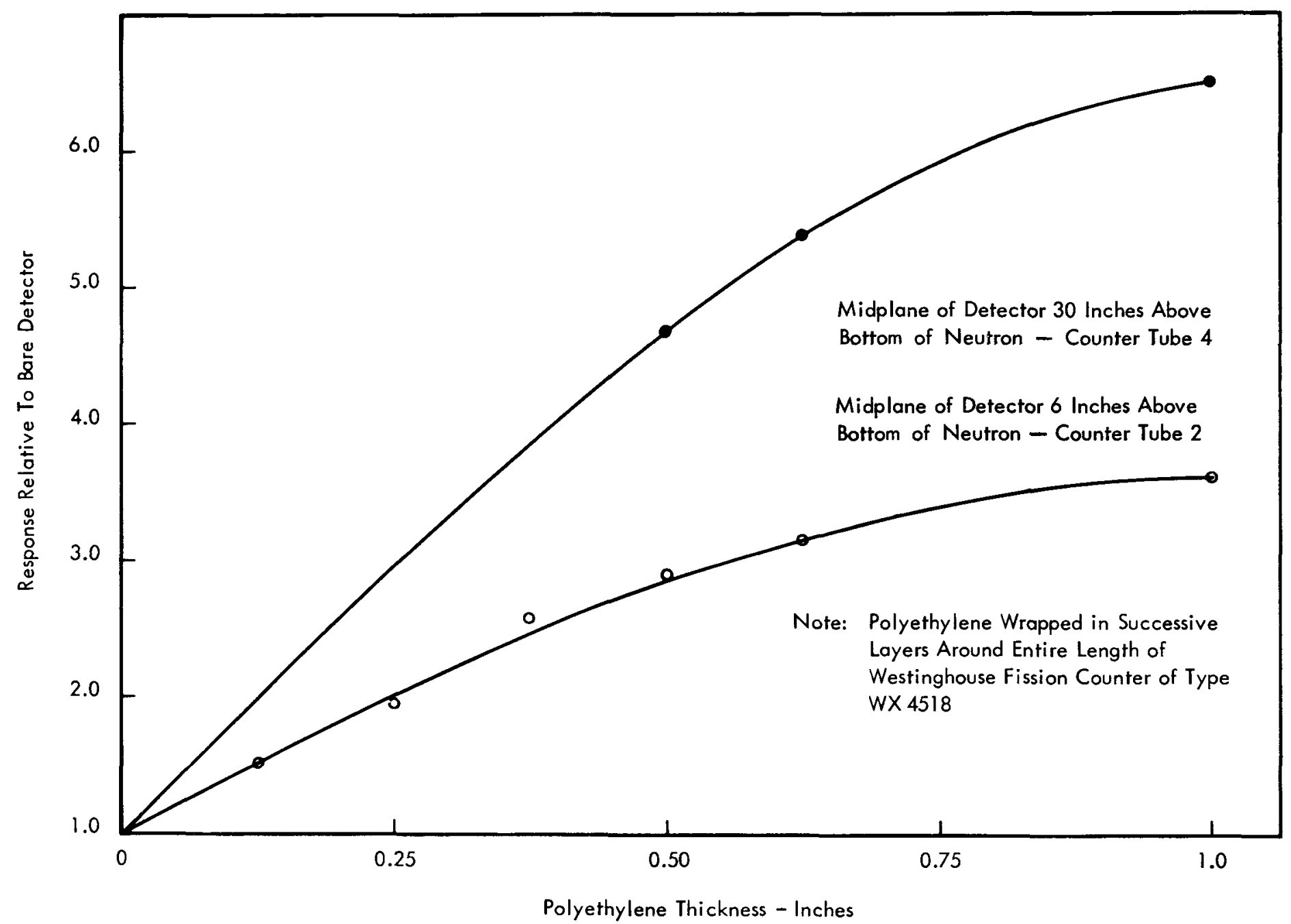

FIG. 13 EFFECT OF POLYETHYLENE ON FISSION COUNTER IN NEUTRON - COUNTER TUBES 2 AND 4 


\section{SHUTDOWN POWER LEVEL MEASUREMENTS}

One goal of the present test was to determine the size of the antimonyberyllium neutron source needed to produce a minimum of $10 \mathrm{cps}$ on the source range channels of the permanent plant instrumentation at shutdown conditions, i.e., all control rods and safety rods fully inserted at the refueling temperature of $517 \mathrm{~F}$ is othermal. Since the permanent plant source range responses obtained earlier (Section IV. A2)were normalized on the basis of the response per watt of reactor power, all that was required was to determine the power level of the reactor at shutdown that resulted from the subcritical multiplication of a neutron source of known source strength. These results could then be scaled accordingly, using the detector response data to obtain the desired source strength. The results of the shutdown power level measurements are given below.

\section{Evaluation of Shutdown Power Level}

The required relationship needed for the source strength determination is conveniently expressed as the ratio of the neutron source strength to shutdown reactor power ( $\mathrm{S} / \mathrm{P}$ curies per watt). The data were taken on October 15, 1963, and a re summarized below:

a. Source Location - Core lattice position N05-N04, i.e., the permanent source position (Figure 2).

$$
\begin{aligned}
& \text { b. Source Strength }-132 \text { curies of Sb-124 (Figure 14). } \\
& \text { c. Reactor Temperature }-517 \mathrm{~F} \text { isothermal. } \\
& \text { d. Excess Reactivity Before Shutdown }-37.5 \text { cents. } \\
& \text { e. Shutdown Power }-0.128 \text { watts. }
\end{aligned}
$$

Therefore, the source strength required per watt of shutdown power for the reactor conditions existing on October 15, 1963, is

$$
S / P=\frac{132}{0.128}=1032 \text { curies } / \text { watt }
$$

However, to be conservative the above value of $S / P$ should be re-evaluated for the condition of zero excess reactivity, i.e., the condition of minimum subcritical source multiplication or minimum shutdown power. To make the re-evaluation, it is reasoned that had the seven safety rods (worth $\$ 8.00$ )

* Determined from the count rates obtained on the two source range power monitoring channels of the temporary startup instrumentation (Channel $1=$ $477.5 \mathrm{cpm}$; Channel $2=552.1 \mathrm{cpm}$ ) and the power calibration data of Table VI. 


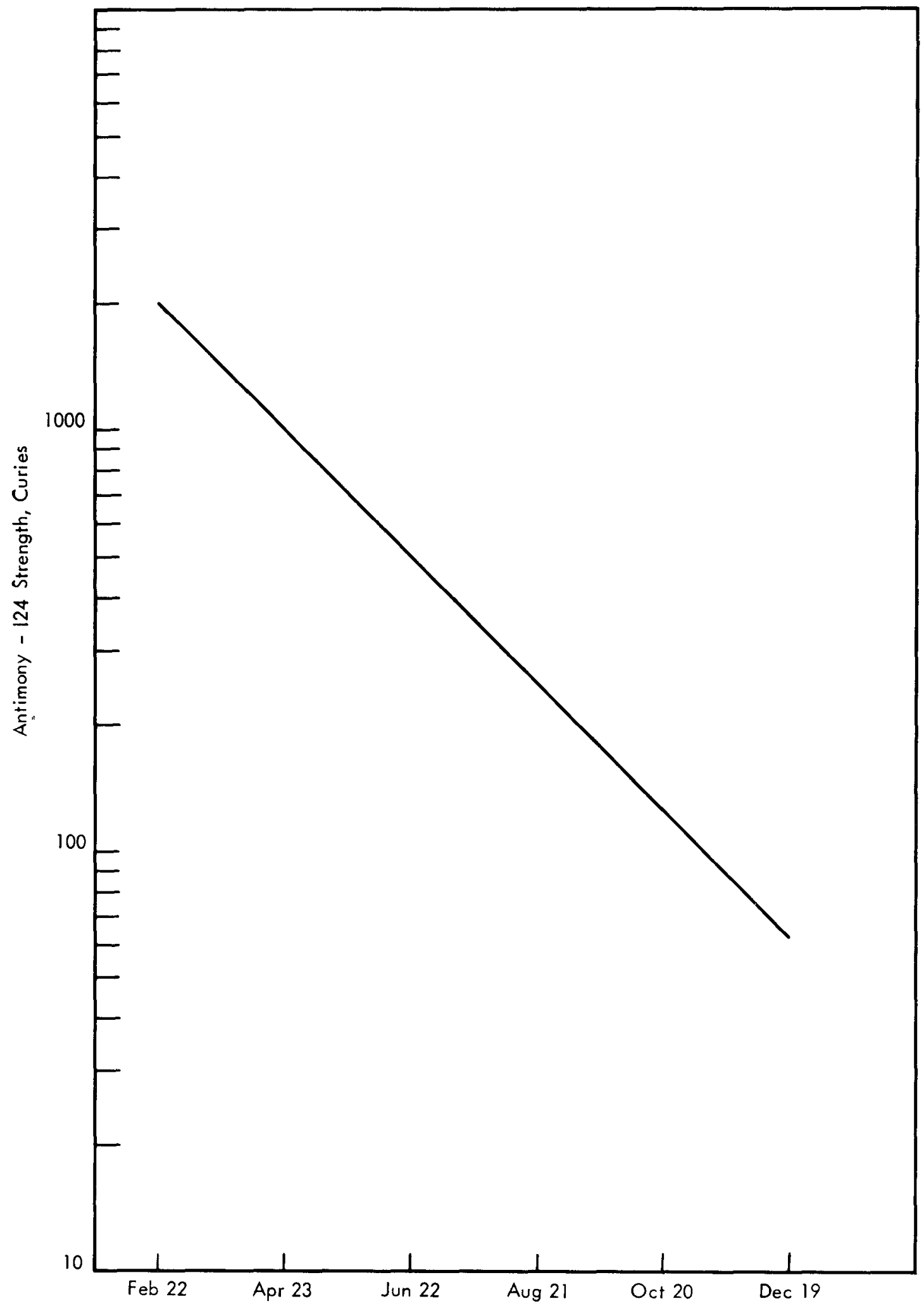

FIG. 14 DECAY CURVE FOR ANTIMONY-BERYLLIUM SOURCE NO.2 
and two control rods (worth 92 cents) been inserted from a condition of zero excess reactivity, instead of 37.5 cents excess, the shutdown power would have been,

$$
\begin{aligned}
P_{2} & =P_{1}\left(R_{1} / R_{2}\right)^{*} \\
& =0.128\left(\frac{8.92-0.375}{8.92}\right) \\
& =0.123 \text { watts }
\end{aligned}
$$

Therefore, the new source requirement becomes,

$$
S / P=\frac{132}{0.123}=1079 \text { curies } / \text { watt }
$$

This value of $\mathrm{S} / \mathrm{P}$ can then be used to determine the source strength, $\mathrm{S}_{O}$, required for $10 \mathrm{cps}$ on the permanent source range instruments using the following equation,

$$
S_{0}=\left(\frac{10 c p s}{R_{s} / 60}\right)(S / P) \text { curies }
$$

where $\quad R_{S}=$ the normalized response of the permanent source range detectors in their final locations, $\mathrm{cpm} /$ watt

These results are reported later in Section V.A3.

2. Uncertainty in Evaluation

The calculations above can be repeated for data corresponding to shutdown reactor conditions on a different day, for example, October 14 , 1963.5 This was done and the results predicted an $S / P$ value 8.5 percent higher than obtained above. However, statistical analys is of the uncertainties in the data allows a discrepancy of only \pm 6 percent. Therefore, to be conservative, an uncertainty of \pm 10 percent is attached to the value of $S / P$ obtained above.

\section{Dependence on Number of Installed Safety Rods}

There is some uncertainty at this time as to the number of safety rods to be employed for the nominal operation of Core A. Since the shutdown power is a function of shutdown reactivity, as well as the source strength (Equation 4), the value of $S / P$ is dependent on the number of safety rods em-

* This equation as sumes that simple subcritical multiplication theory is valid, i. e., $\mathrm{Ma} l / 1-k_{\text {eff. }}$ Therefore, $R^{s}$ is the shutdown reactivity. 
ployed. This dependence on the shutdown reactivity can be estimated by using the $7-\operatorname{rod} S / P$ value given by Equation 5 and scaling it as follows:

a. Assume that the worth of each of the ganged safety rods is $\$ 1.14$.

b. Assume that the shutdown power is proportional to $1 / 1-k_{\text {eff }}$.

c. Assume that the worth of the two control rods is 92 cents.

Thus, it follows that if $\mathrm{N}=$ the number of installed safety rods,

$$
S / P=\frac{1.14 N+0.92}{8.90} \times 1079 \text { curies } / \text { watt }
$$

For example, consider the case where there are eight installed safety rods which are inserted from a condition of zero excess reactivity. The value of $\mathrm{S} / \mathrm{P}$ becomes,

$$
\begin{aligned}
S / P & =\frac{1.14(8)+0.92}{8.90} \times 1079 \\
& =1218 \text { curies } / \text { watt }
\end{aligned}
$$

\section{SHUTDOWN GAMMA DOSE MEASUREMENTS}

The raw data obtained from the gamma dose rate flux mapping experiments in the neutron counter tubes after shutdown following a given power run consisted of the gamma dose rate as a function of position in each neutron counter tube and the time of the measurement. A consistent presentation of these data required that all the data be extrapolated to a single time after shutdown since the gamma sources were decaying with time. Shielding analysis studies predict that the major source of gammas at the neutron counter tubes is 15 -hour half-life $\mathrm{Na}-24$ in the nearby sodium piping. ${ }^{6}$ This half-life was therefore used to extrapolate all the measured dose rates, $D(t)$, from the actual time of their measurement, $t$, to the single chosen time after shutdown of 3.7 hours. The equation used was

$$
D(3.7)=D(t) \exp \frac{0.693}{15}(t-3.7)
$$

where

$$
t=\text { the actual time after shutdown of the mea- }
$$
surement inhours.

All values were normalized to the single time after shutdown of 3.7 hours because it corresponded very closely to the actual time after shutdown of the measurements made in NCT's 2 and 5, and therefore it minimized the 
extent of the above extrapolation for these two counter tubes. This was desirable because there was evidence that in NCT's 2 and 5 there was a strong gamma component after shutdown with a half-life of 2.6 hours due to $\mathrm{Mn}-56$ activation in stainless steel. (See Section V.D3.) Hence, by minimizing the extrapolation of the data from these two counter tubes in Equation 9, extrapolation errors due to the wrong choice of half-life were kept to a minimum.

The resulting gamma dose rate distributions obtained in NCT's 1 through 6, and a description of the reactor power run on which they were based, are given in Figure 15. 


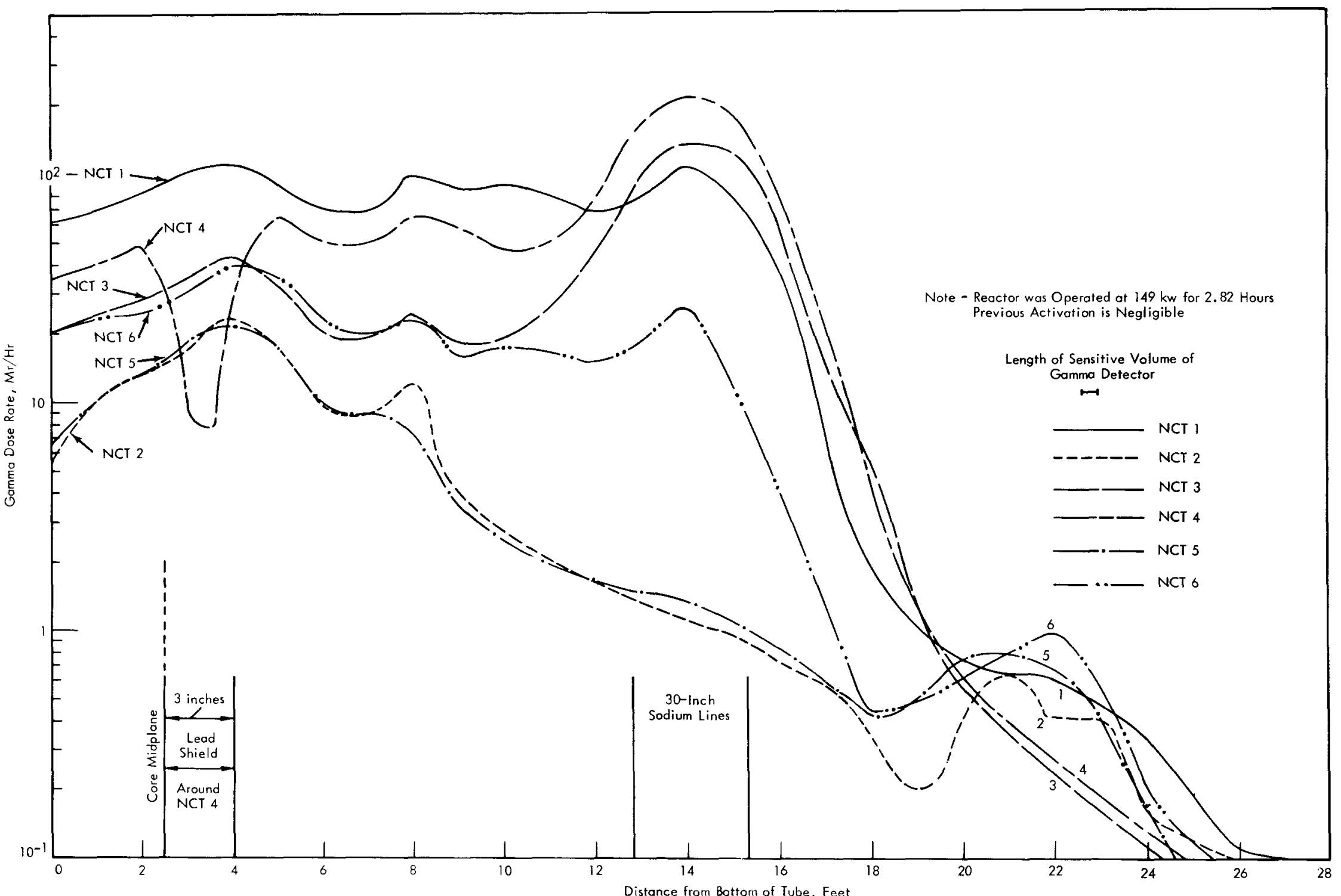

FIG. 15 SHUTDOWN GAMMA DOSE RATE AXIAL DISTRIBUTION IN NEUTRON-COUNTER TUBES 3.7 HOURS AFTER REACTOR SHUTDOWN 


\section{DATA ANALYSIS AND DISCUSSION OF RESULTS}

\section{A. PERMANENT PLANT NEUTRON DETECTOR LOCATIONS AND MINIMUM SOURCE SIZE REQUIRED}

The primary purpose of the flux mapping measurements was to determine the required locations of the permanent plant neutron detectors and the required minimum neutron source size to assure that adequate reactor control and safety could be achieved both during reactor startup and during operation at power. To obtain this information from the experimental data, some general ground rules first had to be established. The data were then analyzed in a straightforward manner, using the ground rules as guidelines, to obtain the proper locations for the source range, intermediate range, and power range detectors and to determine the minimum source size.

\section{General Ground Rules}

Listed below are the ground rules and assumptions upon which the analyses of the detector location and source strength requirements were based.

1. The permanent source is to be located in subassembly position N05-N04 (Figure 2).

2. The shutdown reactivity corresponds to 8 safety rods and the two operating control rods being fully inserted at the condition of zero excess reactivity.

3. The shutdown count rate on the permanent source range channels must be at least $10 \mathrm{cps.*}$

4. The maximum reliable count rate on a source range channel is $2 \times 10^{5} \mathrm{cps}$. Thus, the total useful source range coverage is $2 \times 10^{4}$.

5. There must be an overlap of at least one decade between the source range and intermediate range channels and between the intermediate range and power range channels over which accurate period data can be obtained.

* The required count rate for startup has subsequently been revised to 5 cps. 
6. The chamber current range on the intermediate range channels over which reliable period information is obtainable is between $4 \times 10^{-10}$ and $4 \times 10^{-4}$ amps (six decades).

7. The intermediate range channels must give reliable coverage up to a power level of at least $200 \mathrm{Mwt}$.

8. The maximum current in the intermediate range channels due to noise and/or gamma interference should be about one decade below $4 \times 10^{-10}$ amps.

9. The gamma sensitivity of a compensated intermediate range detector is $3 \times 10^{-13} \mathrm{amps} / \mathrm{R} / \mathrm{hr}$.

10. The power range channel electronics require that the full scale reading of $300 \mathrm{Mwt}$ ( 150 percent of full power) corresponded to an ion chamber current of between $0.2 \times 10^{-3}$ and $3.0 \times 10^{-3}$ amps.

11. There must be one 700-percent-of-full-power power range channel. The electronics of this channel require $1.0 \times 10^{-4}$ amps for full scale deflection (1400 Mwt). This channel will provide power range coverage from $14 \mathrm{Mwt}$ to $1400 \mathrm{Mwt}$.

12. The revised permanent plant Reuter-Stokes intermediate range and powe $r$ range detectors and circuitry will have approximately the same response as the Anton ion chamber whose performance is described in Tables IV and V.

13. The revised permanent plant Westinghouse two-connector source range detector and circuitry will have approximately the same response as the Westinghouse one-connector fission counter whose performance is described in Tables IV and V and Figure 9.

14. There are three source range detectors, one of which is a spare.

15. There are four intermediate range detectors, one of which is a spare.

16. There are six power range detectors, one of which is a spare.

17. No more than two detectors can be located at any one elevation on any one support rack. 
18. There should be a minimum of approximately 19 inches between the top of any given detector and the bottom of the detector above it so as to allow ample space for cable bending and the support racks.

19. The power range channels must cover the range from $2 \mathrm{Mwt}$ to $300 \mathrm{Mwt}$.

20. The current range of the uncompensated ion chamber to be used in the power range channels is approximately $8 \times 10^{-10}$ to $8 \times 10^{-4}$ amps.

\section{Location of Detectors}

Using the above ground rules, the permanent plant detector locations were determined as follows. First, the intermediate range and source range detectors were positioned to (1) obtain one decade of overlap between the source range and intermediate range channels (2) reliably cover the power range between shutdown power and a minimum of at least $200 \mathrm{Mwt}$ and (3) minimize the shutdown power required to produce $10 \mathrm{cps}$ on the source range channels. The power range detectors were than positioned to provide at least one decade of overlap with the intermediate range channels and to reliably extend the power coverage up to at least $300 \mathrm{Mwt}$.

a. Location of Intermediate Range Channels - The intermediate range detector positions were chosen first since they were the most critical, i. e., they have to cover the greatest power range and overlap with both the source range and power range detectors. The first consideration made in the positioning of the intermediate range ion chambers was the choice of the neutron counter tubes to be used. The gamma background requirements (Ground Rules 8 and 9) were the determining factor here, and analysis of the gamma ray data obtained earlier (see Section V.Dld) indicated that the intermediate range detectors must be placed in NCT's 2 and 5 to minimize the gamma background from the sodium piping. Thus, it was decided that two detectors would be located in each of the NCT's 2 and 5 (Ground Rule 15).

Lastly, the elevation of the detectors in the two neutron counter tubes had to be decided upon. The hypothetical optimum elevation for the intermediate range channels such that the required neutron source is minimized would be an elevation that would result in the maximum chamber current of $4 \times 10^{-4}$ amps (Ground Rule 6) being produced at the minimum power level required $(200 \mathrm{Mwt}$ ) at the upper end of their coverage (Ground Rule 7). However, this would require an intermediate range detector response of $2 \times 10^{-12} \mathrm{amps} / \mathrm{watt}$ and the experimental data indicate that this is not obtainable at any position in either NCT 2 or 5 . The most sensitive position that can be obtained for these detectors in either NCT's 2 or 5 is a 
position 15 inches (sensitive volume midplane elevation) from the bottom of the neutron counter tube (Figures 6 and 7 ). The absolute response of the Anton B-10-lined ion chambers in this position, using the data from Table V, Figure 7, and Section IV.A3) is then found to be $0.328 \times 10^{-12} \mathrm{amps} /$ watt.* This position of maximum sensitivity was the refore chosen for the position of the permanent plant intermediate range detectors in both NCT's 2 and 5 in order to minimize the source requirements (Ground Rule 17). The power range covered by the intermediate range channels, based on a sensitivity of $0.328 \times 10^{-12}$ amps/watt and Ground Rule 6, thus becomes 1220 watts to $1220 \mathrm{Mw}$.

\section{b. Location of Source Range Channels}

With the intermediate range detectors positioned as outlined above, the three source range fission detectors (Ground Rule 14) were then positioned in NCT 3 as follows. First, to obtain the optimum positioning of the source range detectors for minimization of the required neutron source strength, the requirement was set that their maximum count rate of $2 \times 10^{5}$ cps (Ground Rule 4) be obtained at a power level of 12,200 watts, thus providing the minimum required one decade of overlap with the intermediate range channels (Ground Rule 5). For this condition to be fulfilled, the source range detectors had to be positioned so that they had a sensitivity of 983 $\mathrm{cpm} /$ watt. From Figure 9 it was determined that this sensitivity could be attained by placing the midplane of the sensitive volume of the source range detectors 23.6 inches from the bottom of NCT 3. This position was therefore chosen for the two operational permanent plant source range fission counters in NCT 3.** The third spare detector will not be installed in the neutron counter tube at present but instead it will be kept on the shelf ready for use if needed. The power range covered by the source range channels, based on a sensitivity of $983 \mathrm{cpm} /$ watt and Ground Rules 3 and 4 , thus becomes 0.61 watts (minimum) to 12,200 watts.

* Table V indicates that the response of the Anton B-10-lined ion chamber was about $0.343 \times 10^{-12}$ amps/watt when positioned at the bottom of either NCT 2 or 5 (detector volume midplane 5.5 inches from the bottom of the tube). Figure 7 shows that the response for a boron detector located approximately 15 inches from the bottom of either NCT 2 or 5 is 5 percent larger than that obtained 5.5 inches from the bottom of the tube. Section IVA 3 indicates that a reduction in detector response of 10 percent should be taken to account for the slight shadowing effect which will result with the two detectors in each counter tube placed side by side at this position. Thus, the effective response is $0.343 \times 10^{-12} \times 1.05 \times 0.90 \mathrm{amps} / \mathrm{watt}$ or $0.328 \times 10^{-12} \mathrm{amps} / \mathrm{watt}$.

*** No correction to the source range detector response to account for shadowing was made (even though the detectors will be placed side by side) because the effect in their case was thought to be negligible. 
c. Location of Power Range Channels - It was decided to reserve both NCT's 3 and 4 for the source range detectors even though the two operational detectors will initially be placed side by side in only NCT 3 . $\mathrm{NCT}^{\prime} \mathrm{s} 2$ and 5 contain the intermediate range detectors. Thus, only NCT's 1 and 6 were available for the unrestricted placement of the six power range detectors (Ground Rule 16).

The experimental results show that when the Anton B-10-lined ion chambers are placed at their most sensitive positions in NCT's 1 and 6 (15 inches from the bottom) they have effective responses of $0.288 \times 10^{-12}$ and $0.231 \times 10^{-12}$ amps/watt, respectively. These values were obtained by scaling the shadowed effective response of $0.328 \times 10^{-12} \mathrm{amps} / \mathrm{watt}$, found 15 inches above the bottom of NCT 2 (Section V.A2a). according to the relative $\mathrm{B}-10$ response distributions for $\mathrm{NCT}^{\prime} \mathrm{s} 1,2$, and 6 shown in Figure 6. These responses yield currents of $0.86 \times 10^{-4}$ and $0.69 \times 10^{-4}$ amps respectively at a power level of $300 \mathrm{Mwt}$, the upper limit of the power range. However, Ground Rule 10 requires that the full scale 300 Mwt reading must correspond to an ion chamber current of between $0.2 \times 10^{-3}$ and $3.0 \times 10^{-3}$ amps. Therefore, it was clear that the sensitivity requirements of the power range detectors could not be met using the original power range electronics.

For this reason, subsequent revisions of the powe $r$ range electronics were made which increased the channel sensitivity by approximately a factor of eight, reducing the current required for full scale deflection at $300 \mathrm{Mwt}$ to the range from $0.25 \times 10^{-4}$ to $3.8 \times 10^{-4}$ amps. The $15-$ inch detector midplane elevation position in NCT's 1 and 6 then met the sensitivity requirement. However, only four detectors (two side by side in each tube) can be accommodated in this manner. It was therefore decided that the remaining two detectors will be placed above the intermediate range detectors in NCT's 2 and 5, one in each neutron counter tube. The space requirements needed between detectors at different elevations in the same neutron counter tube (Ground Rule 18) dictate that the lowest position at which these detectors could be placed is about 56 inches above the bottom of the neutron counter tube based on the detector dimensions given in Table $I$. Using Figure 6 to scale the output of these detectors (unshadowed) results in currents of $0.80 \times 10^{-4}$ and $0.57 \times 10^{-4}$ amps at $300 \mathrm{Mwt}$ for this location in NCT's 2 and 5 respectively. Therefore, these values also meet the electronic sensitivity requirements of the revised electronics. Coverage of the lower limit of $2 \mathrm{Mwt}$ (Ground Rule 19) is easily obtainable with all six detectors since the ion chamber current range extends some six decades below the values at $300 \mathrm{Mwt}$ (Ground Rule 20).

A special power monitor to cover powers up to 700 per cent of full power ( $1400 \mathrm{Mwt}$ ) is to be included as part of the power range instrumentation (Ground Rule 11). The upper positions of either NCT 1 or 6 (56 inches above the bottom) are available for such a detector. Using a sensitivity 
of $0.364 \times 10^{-12}$ amps/watt for an unshadowed Anton ion chamber at $15-$ inches elevation in NCT 2 , and the response distributions between tubes given in Figure 6, the response for the 56-inch midplane detector elevation positions in NCT's 1 and 6 becomes $0.898 \times 10^{-13}$ amps/watt and $0.981 \times$ 10-13 amps/watt, respectively. At $1400 \mathrm{Mwt}$, the corresponding currents become $1.26 \times 10^{-4}$ amps and $1.37 \times 10^{-4}$ amps, respectively. Thus, the current requirements (Ground Rule 11) are met with the detector positioned in either NCT 1 or 6 . The most sensitive location, NCT 6, was finally chosen for the permanent plant power range 700 percent recorder.

\section{Minimum Source Size}

The minimum neutron source size required on the basis of Ground Rules 1 through 3 was found as follows. First, reference was made to Section VA2b where it was shown that with the positions chosen for the permanent source range detectors in $\mathrm{NCT} 3$, the lower limit of the source range coverage (10 cps) is 0.61 watts. Then, reference was made to Section IVC2, Equation 8, where it was shown that a 1218 curie source located in core position N05-N04 is required for 1 -watt shutdown power with the eight safety rods and two control rods fully inserted at zero excess reactivity. From these data, the required minimum source strength for a shutdown count rate of $10 \mathrm{cps}$ becomes

$$
S_{\min }=(0.61)(1218)=743 \text { curies }
$$

If for some reason it is required to use NCT 4 for the source range detectors rather than NCT 3, the maximum sensitivity that can be obtained will only be 0.814 times the value obtainable in NCT 3. (The maximum sensitivity in NCT 4 is obtained by placing the detectors 26 inches from the bottom of the tube [see Figure 9].) Thus, if the source range detectors are placed in NCT 4 , the source strength requirement becomes

$$
S_{\min }=\frac{743}{0.814}=913 \text { curies }
$$

\section{Summary of Permanent Plant Detector Positions}

The preceding analysis was used to specify a preliminary estimate of the location (NCT number) and elevation of each neutron detector to be used in the permanent plant neutron detection system. These positions are summarized in Table VII with the elevations being expressed in terms of the distance from the bottom of the neutron counter tube to the midplane of the sensitive volume of the detector.

When the detectors were finally placed, however, the final positioning arrived at for the detectors did not correspond exactly to the elevations specified above. This was due to slight differences which existed in 
TABLE VII - FINAL POSITIONS OF PERMANENT PLANT NEUTRON DETECTORS

Channel $\quad \begin{gathered}\begin{array}{c}\text { Detector } \\ \text { Type }\end{array} \\ \text { NCT }\end{gathered}$

Source Range

$\begin{array}{ll}1 & 5 \\ 2 & 5\end{array}$

$\begin{array}{llll}3 & 23.6 & 23.6 & (0.5)^{* * * * *} \\ 3 & 23.6 & 23.6 & (0.5)^{2}\end{array}$

Intermediate Range

$\begin{array}{llllll}1 & 8 & 2 & 15 & 16.6 & (3.75) \\ 2 & 8 & 2 & 15 & 16.6 & (3.75) \\ 3 & 8 & 5 & 15 & 16.4 & (3.5) \\ \text { Spare } & 8 & 5 & 15 & 16.4 & (3.5)\end{array}$

Power Range

$\begin{array}{llllll}1 \text { (operational) } & 7 & 2 & 56 & 57.3 & (48.5) \\ 2 \text { (operational) } & 7 & 5 & 56 & 57.4 & (48.5) \\ 1 \text { (safety) } & 7 & 1 & 15 & 14.0 & (4.75) \\ 2 \text { (safety) } & 7 & 1 & 15 & 14.0 & (4.75) \\ 3 \text { (safety) } & 7 & 6 & 15 & 14.0 & (5.8) \\ 700 \% \text { recorder } & 7 & 6 & 56 & 57.2 & (49.0) \\ \text { Spare } & 7 & 6 & 15 & 14.0 & (5.8)\end{array}$

* Numbers refer to detector listings in Table I.

*** Elevation given as distance from bottom of NCT to midplane of sensitive volume of detector.

* * *** Values in parentheses given as distance from bottom of detector rack to bottom of detector.

the physical dimensions of the Anton ion chambers (the detectors assumed in the original analysis) and the Reuter-Stokes ion chambers (the detectors actually installed). Slight differences also arose because of corresponding changes in the mechanical characteristics of the detector cable, revisions of the technique used for cable passage, and other mechanical considerations of a similar nature. The as-installed elevations are also given in Table VII.

The detectors were strapped to racks that were inserted into the neutron counter tubes. The racks are suspended in the neutron counter tubes by means of a flange arrangement and thus do not rest on the tube bottoms. 
For the purpose of the detector mounting on the racks it was convenient to specify detector locations in terms of the distance between the bottom of the rack and the bottom of the detector. This position was found using the detector sensitive volume midplane elevations given in Table VII, the detector dimensions given in Table I, and the distances from the bottom of the neutron counter tubes to the bottom of the racks as given in Table VIII. The resulting positions for detector mounting on this basis are included in Table VII also (the values in parentheses).

TABLE VIII - ELEVATIONS OF NEUTRON DETECTOR RACKS

\begin{tabular}{cc} 
Neutron Counter Tube & Elevation, I \\
\hline 1 & 3.75 \\
2 & 3.35 \\
3 & 17.60 \\
4 & - \\
5 & 3.40 \\
6 & 2.70
\end{tabular}

* Elevation given as distance between bottom of rack and bottom of NCT.

\section{Summary of Permanent Plant Detector Responses}

Predicted Responses - The predicted responses and power coverage of the permanent plant detectors in their final as-installed positions were found by applying the detector response data given in Table $V$ and Figures 6,7 and 9 to the as-installed positions of the permanent neutron detectors in a manner similar to before. These results are summarized in Figure 16 and Table IX.

Measured Responses - When the permanent plant detectors were installed, a measurement was made of their response to reactor power. The results of these later measurements together with the predicted responses are given in Table IX. Note that for all the detectors, the discrepancy between the predicted and final measured value is less than 20 per cent. This agreement implies that the source, intermediate, and power range channels will essentially cover the power ranges intended.

Most of the discrepancies between the predicted and final measured responses of the as-installed permanent plant detectors are due to slight differences in the response of the permanent plant detectors and those 


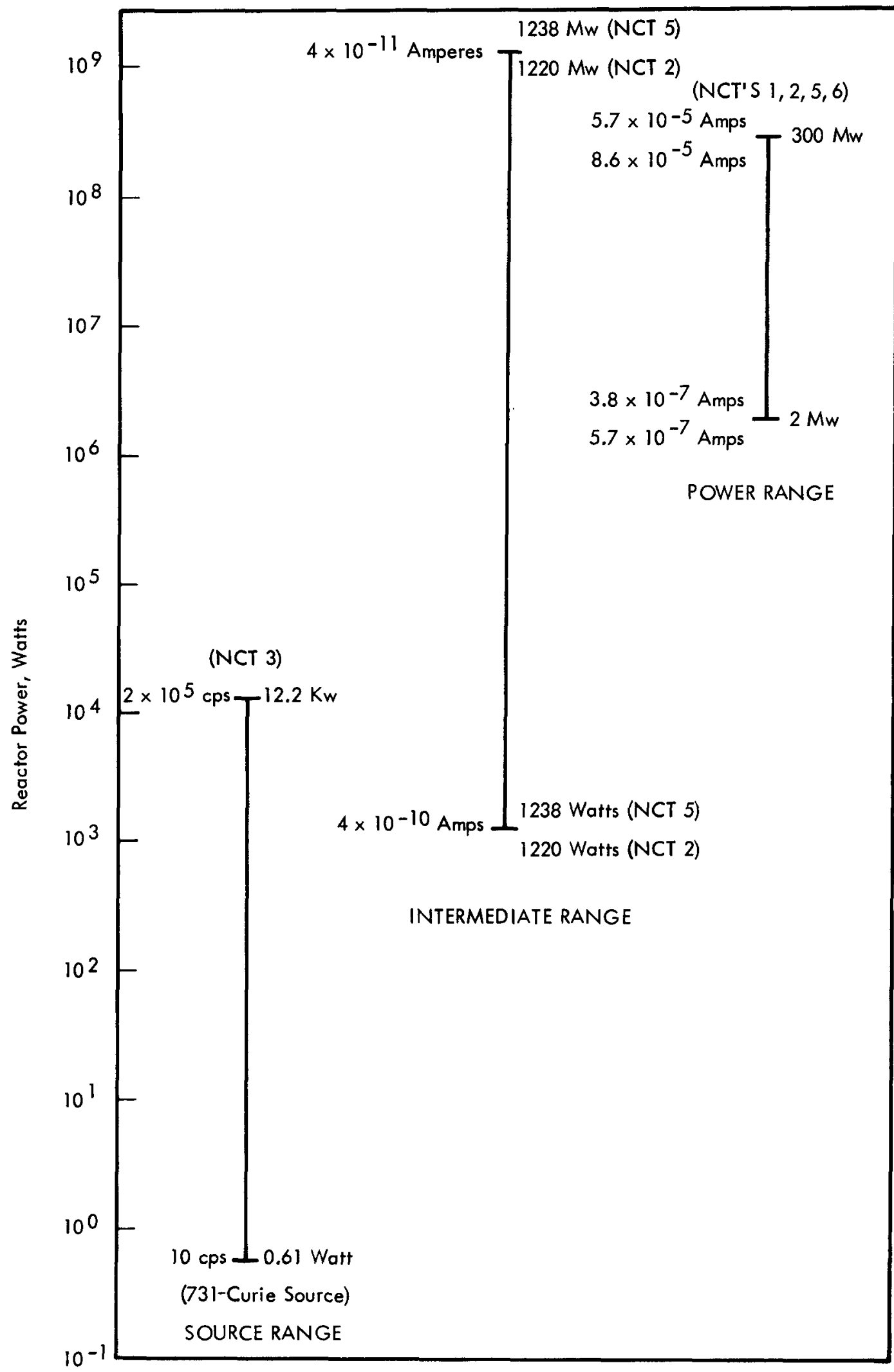

FIGURE 16. PREDICTED REACTOR POWER COVERAGE WITH THE PERMANENT PLANT INSTRUMENTATION 
TABLE IX - MEASURED RESPONSE OF AS-INSTALLED PERMANENT PLANT NEUTRON DETECTORS

Channel

Source Range

1

2

Intermediate Range

1

2

3

Spare
1120

1056

$(\mu \mu \mathrm{amp} / \mathrm{watt})$

0.335

0.299

0.303

0.335

\section{Response}

Predicted,

cpm/watt

983

983

( $\mu \mu$ amp/watt)

$\begin{array}{ll}0.328 & +2.1 \\ 0.328 & -8.8 \\ 0.323 & -6.2 \\ 0.323 & +3.7\end{array}$

Power Range

1 (operational)

0.212

0.252

$-15.9$

2 (operational)

0.156

0.190

$-17.9$

1 (safety)

0.248

0.288

$-13.9$

2 (safety)

0.316

0.288

$+9.7$

3 (safety)

0.242

0.231

$+4.8$

$700 \%$ recorder

0.0762

0.095

$-19.8$

Spare

0.267

0.231

$+15.6$

of the test instrumentation, long term electronic drift that affects the reactor power calibration neutron flux gradients across the neutron counter tubes, and slight differences in the electronics associated with the final measurements as compared to the electronics used for the earlier measurements.

\section{B. SENSITIVITY INCREASE OF SOUR CE RANGE CHANNELS}

The minimum neutron source size required for reactor startup is inversely proportional to the sensitivity of the source range channels. If an additional channel with increased sensitivity were employed, the required source strength would be correspondingly reduced, thereby increasing the time needed between source reloadings and correspondingly decreasing the expense of the source neutrons.

It is planned that such a revision will be made by incorporating two additional source range detectors in NCT 4 (hitherto unused). The detectors will be of the same type as employed in the normal source range channels, i. e., two-connector Westinghouse U-235 fission counters, but their effective sensitivities will be increased by placing them inside a can containing zir- 
conium hydride $\left(\mathrm{ZrH}_{2}\right)$. This will soften the spectrum of the neutrons entering the counter and thus increase the average $U-235$ fission cross section. When required, i. e., at the time of very low source strength, the reactor will be started up with these special high-sensitivity source range channels connected in parallel with the normal source range channels, greatly increas ing the overall channel sensitivity. Then, when a sufficiently high subcritical power level is reached, the high sensitivity channels would be disconnected. The design goal is to increase the maximum sensitivity normally obtainable in NCT 4 by a factor of four. This will decrease the required minimum source strength to 228 curies (Section V.A3) and thereby increase the life of the antimony-beryllium neutron source by about four months ( $\mathrm{Sb}-124$ half-life $\sim 60$ days).

The thickness of $\mathrm{ZrH}_{2}$ required to effect a factor of 4 increase in detector sensitivity was estimated by noting the effect of polyethylene on detector sensitivity in the experiments (Figure 13) and applying a correction factor to take into account the difference in moderating power between polyethylene and $\mathrm{ZrH}_{2}$. Figure 13 indicates that an 0.80 -inch thickness of polyethylene is required to obtain a factor of 6 increase in sensitivity for a U-235 fission counter placed 2. 5 feet above the bottom of NCT 4. Furthermore, $\mathrm{ZrH}_{2}$ is about three-quarters as effective as polyethylene as a moderator, the difference being due chiefly to the differences in the hydrogen density of the two materials. Therefore, it can be expected that about one inch of $\mathrm{ZrH}_{2}$ wrapped around the sensitive portion of a U-235 fission counter will increase the detector sensitivity by about a factor of 6 also. Some uncertainty exists in this extrapolation and in the experiment itself in that possible variations may exist in the moderator effectiveness with detector elevation, etc. Therefore, to assure that the desired factor of 4 increase in detector sensitivity is obtained, a one-inch thickness of $\mathrm{ZrH}_{2}$ is prescribed for the special high-sensitivity source range channel design.

\section{CADMIUM RATIO MEASUREMENTS}

The measured cadmium ratios (Figure 10) are in general agreement with the nearby shield geometry (Figures 11 and 12). The high values (signifying a relatively large thermal flux) occur where there are large areas of plain graphite adjacent to the neutron counter tubes (elevations 571 feet to $576 \mathrm{feet}$ ). The minimum values occur near a large void region (elevation 570 feet) that would afford little moderation and allow high energy neutron streaming to the neutron counter tubes of reactor vessel leakage neutrons. The generally lower values of the cadmium ratio in NCT 1 are probably due to the larger void regions associated with NCT 1 as compared to those associated with NCT 2.

Some attempts have been made to compute the cadmium ratios in the neutron counter tubes using flux distributions obtained from one-dimensional multigroup diffusion theory calculations (Reference 7). However, the calcu- 
lated and experimental results do not agree very well. This is not surpris ing because the reactor geometry is entirely too complex for a one-dimensional calculation to be meaningful. Furthermore, the as-built shield in the vicinity of the neutron counter tubes differs somewhat from that assumed in these early calculations, especially the density of the plain graphite and the percent boration of the inner layer of borated graphite located next to the reactor vessel. It may be possible to perform more meaningful calculations of the cadmium ratio later, using two-dimensional diffusion theory. However, if this is done, great care will have to be taken to assure that an accurate mockup of the shielding geometry is made. Furthermore, there may still be difficulty in correlating the calculated values with the experimental results for the following reasons:

1. There may be boron particles (as contaminants) in the plain graphite. Small amounts of boron have been shown to have a large effect on the calculated thermal fluxes and cadmium ratios in the neutron counter tubes. 8

2. Numerous small cracks and voids exist in the shield with uncertainties as to their number, position, and size.

3. The counter tubes were empty during the experiment and streaming effects may have caused the fluxes at one point to be influenced by those at other points. However, measurements comparing counter responses in empty neutron counter tubes with foil responses in graphite plug-filled neutron counter tubes were performed as part of the shield test program and these results showed no appreciable streaming effects in the lower portions of the tubes. 9 Since this is the region where the permanent plant detectors are to be located, use of the experimental cadmium ratio data in the analysis of their response characteristics should be valid.

\section{GAMMA DOSE RATE AT DETECTOR LOCATIONS}

All the neutron detectors of the type used in the Fermi permanent plant instrumentation system possess a finite sensitivity to gamma irradiation. If their response due to gammas is high relative to the response due to neutrons, it is possible that misleading information could be obtained from the detectors which might in turn lead to an impairment of the safety system of the reactor. For example, if the gammas came from a source that responded slowly to reactor power, the reactor periods measured under these conditions would be longer than the true reactor period. Since this would have safety implications, it was important in the test to verify that the gamma levels at the detector locations would not be excessive. In this respect, both the shutdown and operational gamma doses at the detectors had to be considered. The shutdown gammas are important with regard to their effect on the source range and intermediate range detectors during 
reactor startup when the neutron flux is relatively low; the gamma levels during reactor operation have to be considered primarily at high power level with regard to their effect on the operation of the uncompensated power range channels.

\section{Shutdown Gamma Dose Rates}

The maximum ratio of the gamma dose rate to the neutron flux in the neutron counter tubes will occur immediately following scram after a long period of full-power operation. If the decay gamma levels in such a situation are excessive, subsequent reactor startup might be impaired, due chiefly to the masking of the neutron responses of the intermediate range detectors by the gammas and also because of possible gamma interference with the source range detectors. Therefore, the decay gamma dose rates to be expected at the source range and intermediate range detector locations following reactor shutdown after long-term operation at $200 \mathrm{Mwt}$ had to be determined.

a. Scaling Factor for Maximum Conditions - The shutdown gamma doses following reactor operation were determined for the maximum (worst) conditions which will exist in the reactor, i. e., immediately following (zero decay time) long-term operation at $200 \mathrm{Mwt}$ power. The dose rates were determined for these conditions by using the experimentally determined gamma dose rate values and experimental irradiation conditions, shown in Figure 15, at the appropriate detector positions, and scaling them up to the saturated full power condition described above. In the extrapolation, it was assumed that the primary source of decay gammas is $\mathrm{Na}-24$ (15-hour halflife) located in the nearby sodium pipes (see Figure 3). The scaling factor, $F$, used to multiply the dose rate values of Figure 15 to arrive at the desired dose rates was:

$$
\begin{aligned}
F & =\frac{\text { Saturated Na Activity Immediately After Shutdown from } 200 \mathrm{Mwt}}{\text { Na Activity Measured in Experiments }} \\
& =\frac{200 \times 10^{6} \times A_{O}}{P_{e} \times A_{O}\left(1-e^{-\lambda t_{O}}\right) \times e^{-\lambda t_{s}}}
\end{aligned}
$$

where $\mathrm{A}_{\mathrm{O}}=$ saturated $\mathrm{Na}-24$ activity per watt of reactor power

$\mathrm{P}_{\mathrm{e}}=$ reactor power during the experimental irradiations $=149 \times 10^{3}$ watts

$\mathrm{t}_{\mathrm{O}}=$ irradiation time during experiment

$=2.8$ hours

$\mathrm{t}_{\mathrm{s}}=$ decay time after reactor shutdown of dose measurements $=3.7$ hours 


$$
\begin{aligned}
\lambda & =\mathrm{Na}-24 \text { decay constant } \\
& =0.046 \text { hour }^{-1}
\end{aligned}
$$

Therefore,

$$
F=\frac{\left(\frac{200 \times 10^{6}}{149 \times 10^{3}}\right) \mathrm{e}^{(0.046)(3.7)}}{1-\mathrm{e}^{-(0.046)(2.8)}}=1.3 \times 10^{4}
$$

b. Dose on Source Range Detectors - When the above scaling factor is applied to the experimentally determined gamma doses given in Figure 15, the maximum shutdown gamma dose rate at the position of the permanent source range detectors (23.6-inches elevation in NCT 3 ) becomes $364 \mathrm{R} / \mathrm{hr}$. Gamma interference from space charge effects, which results in decreased neutron sensitivity, requires gamma dose rates of the order of $10^{6} \mathrm{R} / \mathrm{hr}$ or more so that there should be no influence of the shutdown gamma rays on the effective sensitivity of the source range detectors. Furthermore, since the source range detectors are fission counters, it will be relatively easy to discriminate against any unwanted gamma pulses which do occur, the ionization energy loss associated with fission fragments being much greater than that associated with gamma rays. Thus, there should be no interference with source range detector operation due to gammas.

c. Dose on Intermediate Range Detectors - When the above scaling factor is applied to the experimentally determined gamma doses given in Figure 15, the maximum shutdown gamma dose rate at the position of the intermediate range detectors (16.6- and 16.4-inches elevation in NCT's 2 and 5) becomes $148 \mathrm{R} / \mathrm{hr}$. The published gamma sensitivity of the Anton (Lionel) Type 807 compensated B-10-lined ionization chambers is $3 \times 10^{-13}$ amps/R/hr.10 Therefore, the maximum shutdown current due to gammas becomes

$$
\begin{aligned}
I_{\max }(\text { gamma }) & =(148)\left(3 \times 10^{-13}\right) \\
& =4.4 \times 10^{-11} \mathrm{amps}
\end{aligned}
$$

The lower limit of the chamber current on the intermediate range channels is $4 \times 10^{-10}$ amps (Ground Rule 6); therefore, the maximum shutdown gamma field produces about 10 percent of the total current at the lower limit of operation, Ground Rule 8 is satisfied, and the shutdown gammas should not affect the operation of these detectors either.

There are some indications that the as-installed Reuter-Stokes detectors which were substituted for the Anton detectors in the revised permanent plant design may possess a slightly greater gamma sensitivity than that assumed above, thus slightly exceeding the maximum allowable 10 percent value. However, it also appears that the major gamma component in 
$\mathrm{NCT}^{\prime} \mathrm{s} 2$ and 5 immediately following reactor shutdown actually comes from Mn-56 activity in nearby structural stainless stee1, with a half-life of 2.6 hours, rather than from 15 hour half-life $\mathrm{Na}-24$, as as sumed in the preceding analysis (see Section V.D3). When a similar extrapolation of the data in Figure 15 is made on this new basis, the resulting doses at the positions of the permanent intermediate range detectors in NCT's 2 and 5 are lower than those obtained above by assuming $\mathrm{Na}-24$ to be the primary gamma contributor. (See Section V.D3.) Thus, even if it proves true that the as-installed Reuter-Stokes detectors do actually have a slighter greater gamma sensitivity than the Anton detectors, the gamma interference in these detectors during startup should be below the maximum allowable 10 percent value.

Figure 15 clearly indicates that the smallest decay gamma dose rates are seen in NCT's 2 and 5 . Since the gamma level in even these neutron counter tubes is marginal, it is obvious that the remaining neutron counter tubes, where the neutron flux levels are not significantly different, are precluded from use for the intermediate range detectors.

\section{Operating Gamma Dose Rates}

After reactor startup, when the reactor is being brought up to its operating power level, a change will occur in the distribution of the gamma-ray sources giving rise to the gamma dose at the neutron counter tubes, i.e., as the power increases, prompt gammas (resulting from ( $n, a)$ reactions in reactor structural materials) will become more important than the decay gammas. This will not harmfully affect the operation of the source range and intermediate range detectors since by then the neutron flux at these detectors will have increased greatly. However, the operating gamma dose rates at the neutron counter tubes are of importance in evaluating the performance of the power range detectors since they are to be operated uncompensated (Section II. C). Therefore, the operating gamma dose rates expected at the power range detector locations had to be determined also.

a. Method of Analysis - The as-installed positioning of the six permanent plant power range detectors is given in Section V. A4. Table VII. Two detectors each are located in NCT's 1 and 6 (14 inches elevation) and one detector each is located in NCT's 2 and 5 (57 inches elevation). The operational gamma dose rates in NCT's 1 and 2 during low-power reactor operation have already been measured as part of the shield test program. 11 For the purpose of the analysis, the dose rates in $\mathrm{NCT} 6$ were assumed identical to those in NCT 1 and those in NCT 5 identical to those in NCT 2. These neutron counter tubes are at essentially symmetric positions in the graphite shield (see Figure 3), and therefore should have approximately the same operational gamma dose rates.

To determine the effect of the operational gammas on the power range detectors, it was then necessary only to pick a power level and 
determine the ion chamber current due to gammas compared to the current due to neutrons for each detector at this power level. This is valid because it may be assumed that the operating gammas dose rate is proportional to the neutron flux and the ratio of the two will be the same at all power levels.

b. Dose on Power Range Detectors - The comparison between the ion chamber gamma and neutron currents for each power range channel was made at the power level corresponding to full scale deflection (300 Mwt or 150 percent of full power) and the results are summarized in Table IX. The operational gamma dose rates at $300 \mathrm{Mwt}$ were obtained by scaling up the measured values obtained at $800 \mathrm{kwt}$ in the shield tests ${ }^{1}$ directly with power, and the doses were then converted to uncompensated ion chamber currents using the published sensitivity for the Reuter-Stokes chambers of $5 \times 10^{-11}$ amps/R/hr. 12 The $300 \mathrm{Mwt}$ power range ion chamber neutron currents were obtained using the predicted values given in Figure 16.

As can be seen from Table $X$, for all positions of the permanent plant power range detectors the gamma component of the ion chamber current is less than 5 percent of the total current. Substantially greater fractions than this can be tolerated since the operating gamma dose rate is proportional to reactor power and there is effectively no difference between the neutron and gamma ray signals. Thus, there should be no interference on the power range detectors due to gamma rays during reactor operation.

\section{TABLE $X$ - OPERATING GAMMA DOSE RATES AT POWER RANGE DETECTOR POSITIONS AT $300 \mathrm{Mwt}$}

\begin{tabular}{|c|c|c|c|c|}
\hline $\begin{array}{l}\text { Power } \\
\text { Range } \\
\text { Detector } \\
\end{array}$ & $\mathrm{NCT}$ & $\begin{array}{c}\text { Elevation, } \\
\text { Inches } \\
\end{array}$ & $\begin{array}{c}\text { Dose Rate, } \\
\mathrm{R} / \mathrm{hr} \\
\end{array}$ & $\begin{array}{c}\text { Ion Chamber } \\
\text { Current from Gammas, } \\
\% \text { of Total } \\
\end{array}$ \\
\hline 1 (operational) & 2 & 57.3 & 37,600 & 2.5 \\
\hline 2 (operational) & 5 & 57.4 & 37,600 & 3.5 \\
\hline 1 (safety) & 1 & 14.0 & 27,000 & 1.5 \\
\hline 2 (safety) & 1 & 14.0 & 27,000 & 1.5 \\
\hline 3 (safety) & 6 & 14.0 & 27,000 & 1.9 \\
\hline Spare & 6 & 14.0 & 27,000 & 1.9 \\
\hline
\end{tabular}

* Elevation given as distance from bottom of NCT to midplane of sensitive volume of detector. 


\section{Source of Shutdown Gammas}

A meaningful extrapolation of the measured gamma dose rates obtained after shutdown (shown in Figure 15) to conditions of long-term reactor operation requires that the effective half-life of the gamma contributors be known. Calculations predicted that the major source of these gammas in the case of all neutron counter tubes is the $\mathrm{Na}-24$ activity contained in the nearby sodium lines. 6 The curves of Figure 15 for NCT's 1, 3, 4, and 6 do actually reflect the geometry of the nearby sodium lines (Figure 3 ). For example, the gamma response in NCT's 3 and 4 exhibits a maximum due to the proximity of the nearby 30 -inch sodium lines, and the responses for all four of these counter tubes fall off sharply at approximately 14 -feet elevation, the elevation at which the sodium lines exit from the primary shield tank. Therefore, the conclusions reached from the calculations appear to be valid in the case of NCT's 1, 3, 4, and 6. However, the curves for NCT's 2 and 5 do not exhibit this clear drop-off at 14 feet, indicating that the major source of gammas in their case may not be due to the $\mathrm{Na}-24$ activity in the sodium lines. As a matter of fact, subsequent measurements were made in NCT 2 of the decay characteristics of the shutdown gamma dose; they revealed an effective half-life considerably shorter than that of 15-hour Na-24 during the first 24 hours after shutdown. After this time, the 15-hour half-1ife Na-24 was then observed. (See Figure 17.) The main constituent of this shorter half-life gamma emitter is believed to be 2.6hour Mn-56 which probably results from neutron capture in the manganese component of the 304-type stainless steel used in the reactor vessel construction. A similar decay measurement was made in NCT 1 and reflected only 15 hour half-life Na-24. This, therefore, confirmed the earlier observation (Figures 15 and 3 ) that the major decay gamma source seen in NCT's 1, 3, 4, and 6 at the neutron detector elevations is probably from sodium activation.

The detection of a possible contribution to the shutdown gamma dose rates in NCT's 2 and 5 from steel activation, rather than from sodium activation, required a re-evaluation of the predicted shutdown gamma doses on the intermediate range detectors in these neutron counter tubes following long-term reactor operation. This was done as follows. First, it was assumed that the primary source of the postulated steel activation was the reactor vessel. Multigroup diffusion theory calculations were then made which indicated that Mn-56 constitutes 85 percent of the total saturated vessel activity. 13 Based on this, an extrapolation of the measured gamma dose values for NCT's 2 and 5 (Figure 15) to the case of long-term operation at $200 \mathrm{Mwt}$, and zero decay time was made by assuming all the measured gammas to be those of 2.6-hour Mn-56. The final result was then increased by 15 percent to account for the other isotopes. The extrapolation was made using Equation 12 and the $\lambda$ value for $\mathrm{Mn}-56$. The resulting dose rate obtained was lower than that obtained by the nominal extrapolation that assumed $\mathrm{Na}-24$ to be the primary gamma source. Thus, it would appear that the previous 


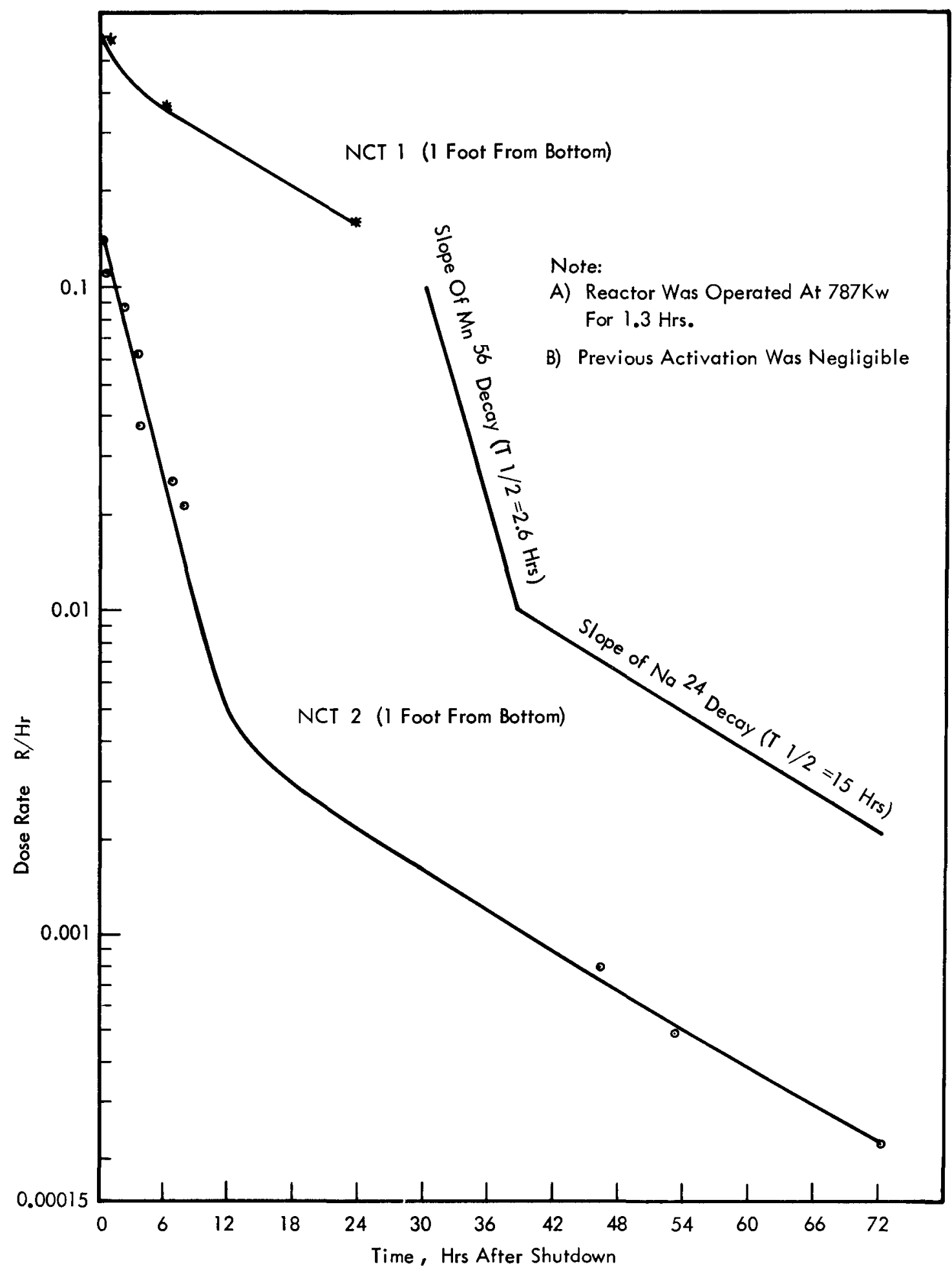

FIG. 17 SHUTDOWN GAMMA DOSE RATES IN NEUTRON - COUNTER TUBES 1 AND 2 AS A FUNCTION OF TIME AFTER SHUTDOWN 
estimate (Section V.Dld obtained by assuming $\mathrm{Na}-24$ to be the primary gamma source is conservative. On this basis, it was concluded that the effect of shutdown gammas on the intermediate range detectors in NCT's 2 and 5 would not be harmful even if the primary gamma source is actually due to the activation of the stainless steel reactor vessel.

\section{E. COMPARISON WITH CALCULATION}

A brief discussion of the agreement between the measured and predicted results of the flux mapping experiments is given below.

\section{Detector Responses}

The general shapes of the measured boron-10 neutron capture and U-235 neutron fission responses in the neutron counter tubes, given in Figures 6 through 9, agree quite well with those predicted from calculations. The effect of the neutron windows located in the inner 6-inch-thick borated graphite layer of the shield just above the core midplane and in front of NCT's 3 and 4 can be seen. The humps in the curves observed at the 8-foot elevation reflect the effect of the reactor vessel transition deck. Although the cadmium ratios measured (Figure 10) indicate a somewhat harder spectrum for the neutron flux than predicted from calculations, good agreement on the cadmium ratio was not expected. (See Section V.C.) Nevertheless, the overall absolute detector responses (Table V) were sufficiently accurately predicted beforehand to allow satisfactory placement of the permanent neutron detectors to be made with only minor adjustments being required in the as-designed electronics.

\section{Shutdown Gamma Dose Rates}

The shutdown gamma dose rates at the elevation of the core midplane in each neutron counter tube were calculated prior to the test and the results are given in Reference 13. These calculations indicated that essentially all of the gammas came from activated sodium in the nearby primary system piping. The calculated values, converted to the operating conditions of the experiment (see Section IV.D) are given in Table XI togethe $r$ with the measured values. As seen, the measured doses in $\mathrm{NCT}^{\prime} \mathrm{s} 1,3,4$, and 6 are somewhat smaller than predicted while the doses in NCT's 2 and 5 are larger than predicted.

It is interesting to note that the agreement between the calculations and measurements is generally improved in the case of $\mathrm{NCT}^{\prime} \mathrm{s} 1,3,4$, and 6 if the calculated values are divided by a factor of two. This is consistent with the observation that the measured sodium activation, obtained by sample extraction, is also lower than that calculated by approximately a factor of two (Reference 14). Similar improvement is not expected in the case of NCT's 2 and 5 since, as pointed out earlier, it is thought that stain- 
TABLE XI - SHUTDOWN GAMMA DOSE RATES IN NEUTRON COUNTER TUBES AT CORE MIDPLANE ELEVATION

NCT Number

Calculated Dose, $\mathrm{mr} / \mathrm{hr}$

Measured Dose, $\mathrm{mr} / \mathrm{hr}$

1

472

91

2

2. 4

15

3

49

31

4

49

34

5

9.2

15

6

83

27

* Dose rates based on the test conditions of $3.7 \mathrm{hr}$ after scram from a power run of $149 \mathrm{kw}$ for 2.82 hours.

less steel activation is the major shutdown gamma contributor for these two neutron counter tubes and the original calculations based on sodium activation underestimate the effect of this source.

\section{Operating Gamma Dose Rates}

Most of the operating gammas at the neutron counter tubes result from neutron capture in the vessel wall.

The calculated operating gamma dose rates in the various neutron counte $r$ tubes and a comparison with the experimental values obtained is given in Reference 11. In general, it was found that the measured values were less than those calculated by roughly an order of magnitude. However, the measured variations with elevation agree fairly well with calculations. Thus, the agreement in variations with elevation lends confidence to the calculated neutron flux distributions at the reactor vessel wall, even though the magnitude of the flux does not agree.

\section{Minimum Source Size}

The minimum source size required for a shutdown count rate of $10 \mathrm{cps}$ on the permanent source range channels was determined to be 743 curies of $\mathrm{Sb}-124$ from the experimental data (Section V. A3). The predicted size, based on multigroup diffusion theory calculations, has been placed at 900 curies. 15 Therefore, the agreement between experimental and calculational results appears to be very good. This is especially true considering the many complex factors involved in such a prediction. However, later investigation has shown that the good agreement apparently found is fortuitous and that it is actually due to two compensating factors. In the first place, the 900 curie predicted value given in Reference 15 was found to be actually 
based on a count rate of $70 \mathrm{cps}$ with the one-connector fission counter instead of $10 \mathrm{cps}$. The extra factor of seven in source strength necessary to achieve the desired count rate was retained in the calculations as a safety margin because of the inherent inaccuracies known to exist in deep penetration diffusion theory flux calculations of this type. Secondly, the experimentally determined 743 curie value has been found to be a factor of two smaller than that actually required. This error resulted from a factor of two inaccuracy in the quoted activity of the source used in the experiments (Figure 14) which was used in the extrapolation of the experimental data (Section V.A3) to obtain the 743 curie value. The source activity data shown in Figure 14 were supplied by the General Electric Test Reactor irradiation facility after they had performed the irradiation. However, later investigation showed that their quoted Sb-124 activity was based solely on thermal neutron activation using out-dated cross sections, and in addition burn-out was not taken into consideration. When epithermal activation and the other two effects are considered, the source activity becomes about double that shown in Figure 14 and the experimentally determined source strength for $10 \mathrm{cps}$ becomes 1486 curies. On this basis, the overall factor, $F$, by which the calculated source required for $10 \mathrm{cps}$ on the permanent source range detectors is actually smaller than the measured value is

$$
F=\frac{1486}{900} \times 7=11.6
$$

This discrepancy is thought to be due to two factors: (1) the tendency for diffusion theory to overpredict the flux at deep penetrations and (2) the fact that the measured cadmium ratios in the neutron counter tubes indicate quite a bit harder neutron spectrum, and hence smaller effective U-235 fission counter cross section, than predicted. (See Section V.C.) 
- 


\section{CONCLUSIONS}

The objectives of this test have been fulfilled. Boron capture and U-235 fission responses in the appropriate neutron detector tubes have been established. All permanent plant neutron detector positions have been designated and the detectors installed. The as-installed detector responses meet the requirements at all power levels of interest. The predicted gamma levels at the detector positions at full power and following full power operation are sufficiently low to permit proper neutron detector operation. The minimum neutron source strength required to give a sufficient shutdown count rate on the source range channels for proper reactor startup was determined and found to be consistent with the source strengths available for the neutron source subassembly. 


\section{REFERENCES}

1. PRDC, "Enrico Fermi Hazards Summary Report and Technical Information", Volumes 1 - 7, as Revised in March 1964.

2. R. E. Horne, "Enrico Fermi Nuclear Test Procedure No. 11, Flux Mapping of Neutron Detector Guide Tubes" (1963).

3. J. Levine, "Test Procedure for Flux Mapping Neutron Counter Tubes No. 3 and 4", APDA Internal Memorandum (November 19, 1963).

4. E. M. Page and R. E. Horne, "Preliminary Evaluation of NTP-2, Absolute Power Calibration", APDA Internal Memorandum, P-63-383 (1963).

5. APDA, "Fermi Nuclear Test Log", Page 120, October 14, 1963.

6. R. E. Mueller, "Gamma Fluxes at the Neutron Detectors after Scram", APDA Internal Memorandum (1958).

7. R. J. Beaudry "Neutron Fluxes and Cadmium Ratios at the Neutron Counter Tubes", APDA Internal Memorandum, P-64-211 (1964).

8. R. E. Mueller, "Nuclear Considerations for Allowable Graphite Oxidation in the Primary Shield Tank", APDA Internal Memorandum, P-62 490 (1962).

9. R. J. Beaudry, "Preliminary Evaluation of Shield Test No. 7, Neutron Streaming in the Neutron Counter Tubes", APDA Internal Memorandum (1965).

10. Lionel Neutron Detector Catalogue, May 1, 1962, Lionel Electronic Laboratories, Inc., 1226-1238 Flushing Avenue, Brooklyn 37, New York.

11. R. J. Beaudry, "Preliminary Evaluation of Shield Test No. 2, Gamma Mapping of the Neutron Counter Tubes", APDA Internal Memorandum, $P-65-81$ (1965).

12. Catalog of Neutron Detectors and Gamma Ionization Chambers, Catalog 7, Reuter-Stokes Electronic Components Inc., 18530 Miles Parkway, Warrensville Heights, Cleveland 28, Ohio.

13. P. DeMyttenaere, "Attempt to Use the Already-Measured Gamma Dose on the Detectors in Predicting the Gamma Dose for Restarting Conditions after Full Power Operation", APDA Internal Memorandum, P-64-187 (1964). 
14. R. J. Beaudry, "Results of the 150 kwt Power Run of the Fermi Reactor", APDA Internal Memorandum, P-64-58 (1964).

15. R. E. Mueller, "Effective Thermal Neutron Fluxes at the Neutron Counter Tubes", APDA Internal Memorandum, P-62-270 (1962). 